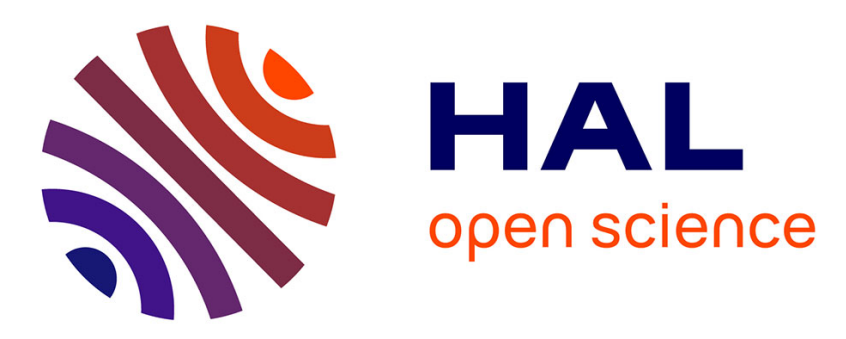

\title{
Culture and Capital Structure: What Else to the Puzzle?
}

Vipin Mogha, Benjamin Williams

\section{To cite this version:}

Vipin Mogha, Benjamin Williams. Culture and Capital Structure: What Else to the Puzzle?. International Review of Financial Analysis, 2020. hal-03043112

\section{HAL Id: hal-03043112 \\ https://hal.uca.fr/hal-03043112}

Submitted on 7 Dec 2020

HAL is a multi-disciplinary open access archive for the deposit and dissemination of scientific research documents, whether they are published or not. The documents may come from teaching and research institutions in France or abroad, or from public or private research centers.
L'archive ouverte pluridisciplinaire HAL, est destinée au dépôt et à la diffusion de documents scientifiques de niveau recherche, publiés ou non, émanant des établissements d'enseignement et de recherche français ou étrangers, des laboratoires publics ou privés. 


\title{
Culture and Capital Structure: What Else to the Puzzle?
}

\author{
Vipin Mogha* \\ PhD Student - Finance, Université Clermont Auvergne, vipin.mogha@uca.fr \\ Benjamin Williams \\ Professor of Finance, Université Clermont Auvergne, benjamin.williams@uca.fr
}

\begin{abstract}
:
This paper investigates four of Hofstede's cultural dimensions -individualism, masculinity, uncertainty avoidance, and long-term orientation- influence on firms' choices of short-term and long-term capital structures. Cultures influence on corporate risk-taking may drive their debt-to-equity mix based on the higher of their equity book or market value. We empirically test culture influence with a sample of 5968 firms from five industry sectors, across 33 countries, over 2009-2017. We find firms national culture influencing their choices of short-term and long-term debt to book and market value of equity. The influence is more significant on the short-term than the long-term capital structures. Furthermore, it is more significant on the short-term debt to market value of equity and on the long-term debt to book value of equity. Our robustness checks at the firm-level, country-level and sample-level confirm and reinforce our main results. These findings would provide financial analysts, investors, and creditors an in-depth understanding when comparing international firms' capital structures.
\end{abstract}

Keywords: Capital structure, National culture, Risk-taking, Debt-to-Equity

JEL Code: G34, Z10

* Corresponding author. Tel.: +33 473177700

IAE Université Clermont Auvergne (UCA), Graduate School of Management, 11 Boulevard Charles de Gaulle, 63000 Clermont-Ferrand, FRANCE 


\section{Introduction}

Firms' choice of capital structure is a much-debated topic, starting with the seminal work of Modigliani and Miller (1958) However, more than seventy years later, it remains a "puzzle" for researchers. Myers (1984) stressed, "we don't know" as an answer to the question of "how do firms choose their capital structures". At first sight, the discussion was about the micro-determinants at firm-level. The choice of the capital is based on financial management considerations. Indeed, managers, which are supposed to operate on behalf of shareholders, determinate the optimal mix of funding. In other words, they allocate between equity and debt by setting the financial leverage, which is the ratio of debt-to-equity. A higher leverage leads to a higher return on equity, but also -on the other side- to a higher financial risk for shareholders (Myers, 1984).

This risk-taking behavior is industry-specific, due to the need in assets, but it should also be rooted in the national culture of firm's country-of-origin (Li et al., 2013). Firms are not pure economical concept doing their best to maximize profit. They embed the culture of their founders and that of national institutions. The way firms are doing business has a cultural component as shown by Williamson (2000).

According to this view, capital structure should be influenced by national culture within the meaning of Hofstede (1980,2001), which defines it as "the collective programming of the mind that distinguishes the members of one group or category of people from another". German managers have a cultural background different from the one Japanese or US managers and both corporate governance and agency issues are influenced by the "social embeddedness" including traditions, practices, norms, and customs (Williamson, 2000).

A recent literature investigates the link between firm financing and culture. According to Chui et al. (2002) and Fauver and McDonald (2015), national culture of firm's country-of-origin is a determinant influencing the ratio of debt-to-total assets. Culture also influences firms' debt-maturity, measured as the long-term debt to total-debt ratio (Zheng et al., 2012; Chang et al., 2012). However, this recent literature does not consider capital structure in its classical approach dealing with the debt versus equity mix. Our paper aims to fill this gap and addresses the following research question: is capital structure influenced by the national culture of firm's country-of-origin.

The concept of capital structure is simple and complex at the same time. Indeed, the definition of the financial leverage as the ratio of debt-to-equity remains vague and few things are said about its measurement. Titman and Wessels (1988) address this issue and propose three pairs of debt-to-equity ratios. On one hand, they split the total debt in three sub-components: short-term debt, long-term debt, and convertible debt. On the other hand, they consider both the book and market value of equity. These three pairs of ratios account for the complexity of firms' capital structure. Leaving aside the convertible 
debt, which is half way between debt and equity, our research focuses on both short and long-term debt versus the book and market value of equity.

The latter distinction refers to the idea of the market timing of debt and equity issuance (Baker \& Wurgler, 2002). It leads firms to time their choice of debt versus their equity book or market value to achieve optimal ratios (Titman \& Wessels, 1988; Ferris et al., 2018). It also highlights the importance of analyzing firms' capital structures with the two-time dimensions of debt and the two dimensions of equity. Beyond these metrics, the idea is to investigate the potential effect of national culture in all aspects of capital structure. This comprehensive approach is part of the novelty of our research.

Similarly, we consider multiple characteristics of culture by the influence of Hofstede's (2001) national culture dimensions of individualism, masculinity, uncertainty avoidance, and long-term orientation on the financial leverage. Our paper conducts an in-depth analysis of the potential effects of each of the four cultural dimension on the debt-equity mix chosen by firms. These hypotheses are then tested based on a broad set of 5968 firms from five industry sectors, across 33 countries, over the 2009-2017 period.

Our first contribution is that the four dimensions of national culture influence all the dimensions of capital structure. This finding adds to the existing body of knowledge by connecting the work of Li et al. (2013), about culture and firms risk-taking, and the research studying the relationship between culture and deb-maturity (Zheng et al., 2012; Chang et al., 2012). Our second key contribution is that the influence of culture is stronger than market forces. Consideration of the market value of equity does not suppress the link between culture and capital structure, which still prevails though altered.

The remainder of the paper is organized as follows. Section 2 presents the literature and our research hypotheses development. Section 3 presents the data sample, variables selection, and the empirical methodology. Sector 4 presents the results, comments, and robustness checks. Section 5 concludes.

\section{Literature and hypotheses}

Firms' search for an optimal capital structure is a never-ending task, which lead them to continuously adjust debt and equity liabilities (Kim, 1982; Ferris et al., 2018). The factors influencing the financing decisions made by firms are numerous (Frank \& Goyal, 2009). These include corporate profits, business growth, collateral assets value, and size. But a growing body of knowledge also suggests that the national culture of firms' country-of-origin may also be central in the financial decisions they make. This leads us to consider the role played by national culture in the design of capital structure. This question is also related to industry-specific patterns. 


\subsection{The capital structure puzzle}

The study of capital structure is an old story but according to Myers (2001), the matter remains unresolved. If we go back to the foundations, we may consider three majors theories of capital structure choice: the trade-off theory (Kraus \& Litzenberger, 1973), the pecking order theory (Myers, 1984), and the market-timing theory (Baker \& Wurgler, 2002).

According to the trade-off theory, the capital structure is an arbitrage (trade-off) between the associated benefits (tax) and the associated cost (bankruptcy) of debt. Within this framework, capital structure trends towards an industry average (static trade-off) or drifts unto acceptable limits (dynamic trade-off). For the tenants of the pecking order theory, firms service their financing needs in a preferred order beginning with retained earnings and then debt raising, and ending with equity issuance. Finally, a third school of thought advocates that market-timing matters. Depending on the actual market conditions, firms choose stock when their price is high and prefer debt when they offer a low level of interest.

However, Myers (2001) observes that none of these three theories can be applied "generally" to explain fir ms' capital structure choices. He highlights that Jensen and Meckling's (1976) agency framework relaxes the hypothesis of perfect information made by Modigliani \& Miller (1958). This may explain why corporate managers sometimes make financing choices that are sub-optimal for shareholders. In this light, Myers suggests that one should look beyond the three classic theories focusing on financial capital. He rather advises to simultaneously investigate both the firm's human capital (the corporate managers) along firm's financial capital.

This insight leads us to consider national culture as a component of firms' financing decisions as being part of human capital. We adopt an agnostic approach from the capital structure theories' perspective, as we posit no underlying assumption about the determinants of capital structure. By doing so we comply with Myers (2001) and Ardalan (2017). From an epistemological perspective, this theory agnostic approach leads us to observe capital structure (without any underlying assumption) in regards to national culture.

Capital structure should also not be considered as an indivisible whole since it differs among industrial sectors. These differences depends on both the economic activity and industry's internal dynamics. The latter can relate to industry's competition, products supply-chains or the specific human capital (Harris \& Raviv, 1991). It is also important to notice that the usage of human capital along with the financial capital is characteristic of an industry sector (MacKay \& Phillips, 2005). Finally, the preferences embedded in human capital, due to the risk-averse nature of managers and habit formation (Campbell \& Rogers, 2018, p134), could lead to different levels of firms' risk-taking. For all those reasons, it should be concluded that both human capital preferences and practices may influence capital structure choices of firms. 
Williamson's (2000) new institutional economics (henceforth NIE) framework may help us bind together the capital structure puzzle. He describes a four level constraints system that may influence firms' capital structure choices. The highest level (level-1) is the social embeddedness that includes national culture. It imposes strong constraints on level-2, which is called the institutional environment. It includes polity, judiciary, and bureaucracy. In turn, it constrains the level-3 that consists in the governance mechanisms that regulates firms' contractual framework. Finally, the lowest level (level-4) is that of firm's agency choices dealing with resources allocation.

The existence of a culture of finance and corporate governance (Ardalan, 2007, 2017) complies with Williamson's framework, corresponding mainly to the level-3. According to Williamson, the higher level of the social embeddedness should theoretically "dominate" the culture of finance and corporate governance. It also brings the evidence that finance is rooted in all the aspects of the nature of society (Lagoarde-Segot, 2016), or in Williamson's social embeddedness. Hence, our research aims at testing the dominance of national culture (at level-1) over that of finance and corporate governance.

\subsection{Culture, institutions, and capital structure}

Hofstede (1980) describes culture as the "broad tendencies to prefer certain states of affairs over others". Culture is by nature quite stable and is only changing over "centuries or millennia" (Williamson, 2000). Cultural values that are acquired during childhood are deep rooted in people's unconscious mind and express themselves throughout life Hofstede (1980). What Williamson (2000) calls "the embeddedness of the informal constraints" of culture is somewhat pointed by North's (1991, p.111): "What is it about informal constraints that gives them such a pervasive influence upon the longrun character of economies?".

Firms' are the foundation of economies and their national culture may have a pervasive influence on their financial choices. In the NIE, the social embeddedness of culture influences both legal and financial institutions. Indeed, culture conditions the development of country's institutions of finance (Kwok \& Tadesse, 2006), legal framework (Porta et al., 1998), and governance (Licht et al., 2005). In turn, these institutions may constrain firm's agency choices, such as financing. We call institutional channel, the transmission of cultural value through country institutions.

Moreover, national culture values of the firm's founder get transmitted into firm's policies and practices (Pan et al., 2017). Consequently, firms' management is constrained by these policies and practices in their financial choices. We call agency channel, the transmission of cultural values through firms' human capital.

To sum up, national culture may influence firms' capital structure choices through the institutional and agency channels. National cultures differences may lead to differences in institutions as well differences 
in firms' financial policies and practices. These differences would percolate down into firms' financial choices showing up in their capital structures. This would be well aligned with the NIE framework

Most of this literature ${ }^{1}$ considers the overall influence of national culture on firm's financial choices irrespective of the influence channel. We keep this approach as well. Hence, our paper inserts in this growing body-of-literature on culture and corporate finance.

\subsection{Hypotheses building}

\subsubsection{Foundations}

While considering the NIE framework, the capital structure of firm may be influenced -among other factors- by the cultural values of its country-of-origin. Both the agency and institutional channels transmit culture's influences on firms' financial choices. On the one hand, culture influence is transmitted through the agency channel as agency's risk-taking can appear in firm's choice of debt and equity (Kim, 1982). On the other hand, culture influence is transmitted through the institutional channel as institutions conditions firms' debt and equity financing choices (Shleifer \& Vishny, 1997; DemirgüçKunt \& Maksimovic, 1998).

We thus posit that national culture values would be embedded in firms' financial risk-taking (Li et al., 2013). Risk-taking could also be accentuated by national culture's congruence in the agency and institutional channels (Noorderhaven \& Harzing, 2003; Pan et al., 2017). For example, a firm founded in France by French founders would demonstrate a higher influence of "country-of-origin" cultural values into firm's financial risk-taking extending to their subsidiaries around the world.

The aim of the research is to analyze the role played by national culture in the capital structure puzzle described by Myers (2001). The answer to this questions relates to risk-taking behavior that are conditioned by the culture values in the country-of-origin of the founders. ${ }^{2}$ We consider the overall influence of culture on debt-to-equity mix irrespective of the channel.

In this research, we define and measure national culture through four of the six cultural dimensions proposed by Hofstede (2001) ${ }^{3}$. The first dimension is Individualism versus Collectivism (IDV). It is from low individualism (high collectivism) to high individualism (low collectivism). In individualist cultures,

\footnotetext{
${ }^{1}$ Confirming the NIE is the growing literature describing the relationships between culture and firms' financial choices using Hofstede $(1980,2001)$ metric. To name just a few studies adopting Hofstede $(1980,2001)$ are, culture and corporate risk-taking (Li et al., 2013; Pan et al., 2017); culture and corporate cash holding (Chen et al., 2015); culture and firms' dividends payout (Fidrmuc et al., 2010); culture, earnings and capital markets (Wijayana \& Gray, 2018).

${ }^{2}$ Firms' earnings may condition their financing choices (Demirgüç-Kunt \& Maksimovic, 1998) showing in their capital structure. Indeed, Li et al. (2013) show that culture influences firms' risk-taking through corporates' earnings volatility. It also suggests that the influence of corporate risk-taking may condition firms' choices of debt or equity financing through earnings volatility.

${ }^{3}$ As two dimensions show higher correlation with the others. See: Annexure table 1 that highlights the reason to exclude the remaining two dimensions of PDI and IVR.
} 
the individual cares for self and its dependents, and in collectivist cultures, the group prevails with the caring for each other.

The second dimension is Masculinity versus Feminity (MAS). It is from low masculinity (high feminity) to high masculinity (low feminity). In high masculinity cultures, men and women tend to be more taskoriented than people-oriented, and more assertive and competitive than caring.

The third dimension of Uncertainty Avoidance (UAI), going from low to high UAI, is about the level of acceptance of ambiguity. It describes the preference for predictable outcomes versus unknown outcomes, irrespective of the time horizon of agents.

The fourth dimension is Long-term versus Short-term orientation (LTO) going from low long-term (high short-term) to high long-term (low short-term). The long-term orientation indicates the preference for the future where one expects the most important events to happen.

\subsubsection{Research Hypotheses}

The NIE theoretical framework and the existing literature linking culture and finance mentioned above ${ }^{4}$ lead us to assume that national culture -considered as a whole- is one of the determinants of firms' capital structure. Cultural values may thus contribute to the understanding of the puzzle.

Therefore, we expect firms' country-of-origin cultural dimensions of IDV, MAS, UAI, and LTO to influence their choices of capital structure. We measure capital structure based on both the short-term and long-term debt-to-equity ratio. We consider both the book and market value of equity to account for the market timing issues underlined by (Ferris et al., 2018). Firms indeed may constantly adjust their financing choices by accounting for differences between equity market value and book value. This reasoning is in line with the market-timing theory (Baker \& Wurgler, 2002). ${ }^{5}$ We thus write our first general hypothesis as follows:

H1. There is an association between national culture dimensions and firms' short-term and longterm debt-to-equity choices of capital structure.

However, there may be differences on how each of the four cultural dimensions would influence the debt-to-equity ratio. To investigates these differences, we propose four hypotheses $\mathbf{H 2 a}, \mathbf{H} 2 \mathbf{b}, \mathbf{H} 2 \mathbf{c}$, and H2d respectively linked to the four following cultural dimension of IDV, MAS, UAI, and LTO.

\footnotetext{
${ }^{4}$ e.g.: Chang et al. (2012) and Zheng et al. (2012).

${ }^{5}$ Kim (1982) describes that the optimal capital structure tends to maximize firm's market value. Furthermore, he highlights that there seems to be a "partial equilibrium relationship between firm valuation and corporate leverage". The "partial equilibrium" may be confirming that firms financing choices of debt or equity are oscillating based on their market or book value of equity (Ferris et al., 2018) further pointing to market timing.
} 


\subsubsection{Influence of individualism on capital structure}

Hofstede $(1980,2001)$ mentions that in individualist cultures (IDV), people care more for their own interests, whereas in collectivist cultures (low IDV), people care more for the group interests. Li et al. (2013) find that individualist cultures influence higher risk-taking. Higher risk-taking could lead to higher debt in the debt-to equity ratio, thus to a higher financial leverage. Furthermore, Zheng et al. (2012) mention that firms in collectivist cultures tend to issue lower maturity debt. It could mean that firms in collectivist culture wish to repay their debt at the earliest to avoid burdening their caring group.

Therefore, firms from individualist cultures may have higher long-term debt in their debt-to-equity. On the contrary, firms from collectivist cultures may take lower risk. Lower risk could be with lower overall debt or rather more short-term debt. Firms' access to the stock market and costs of external financing may condition their choice of debt-to-equity and debt maturity (Demirgüç-Kunt \& Maksimovic, 1998). These choices may also depend on the higher value of their book or market value of equity (Myers, 1984; Ferris et al., 2018). Based on these considerations, develop our second hypothesis as:

H2a. There is a negative (positive) association between individualism and the short-term (longterm) debt-to-equity ratios.

\subsubsection{Influence of masculinity on capital structure}

In masculine cultures (high MAS), Hofstede (2010) asserts that people are task-oriented. There is an emphasis on results, with rewards in line with performance. Furthermore, masculinity is often considered an important characteristic for executive leadership roles (Gleason et al., 2000; Appelbaum et al., 2003). Managers' quest for performance could lead them to search for unlimited financing options to pursue growth, leading them to take higher risk in debt financing (Kim, 1982). This is the agency channel influence of culture.

In masculine cultures risk-taking attitude would be accentuated and incite firms' to achieve higher growth and performance ( $\mathrm{Li}$ et al., 2013), which may be possible by higher levels of financing (Demirgüç-Kunt \& Maksimovic, 1998). In feminine cultures (low MAS), people are more caring, less driven by task oriented performance. Firms in feminine cultures would prefer to limit borrowing to the minimum and pay it at the earliest.

As masculine cultures focus on performance, firms may as well look to raise financing through equity if the market value is high. They may rather prefer to raise debt if the book value is higher (Myers, 1984; Ferris et al., 2018). In all scenarios firms in masculine culture would like to raise as much financing as possible. Considering the pecking order theory, we expect firms first to raise more debt and most likely as long-term debt. Therefore, we expect masculinity to be positively (negatively) related with the longterm (short-term) debt-to-equity ratios, leading to our hypothesis as: 
H2b. There is a negative (positive) association between masculinity and the short-term (longterm) debt-to-equity ratios.

\subsubsection{Influence of uncertainty avoidance on capital structure}

Hofstede $(1980,2001)$ describes uncertainty avoidance (UAI) as anxiety in people facing ambiguous and unpredictable situations. People in higher UAI cultures prefer less ambiguous and more predictable outcomes, including predictability of risky situations. Li et al. (2013) find a negative association between UAI and corporate risk-taking. In high UAI cultures, there tend to be more regulations to create more predictability. Firms in such an environment may prefer the predictability of debt raising from banks than the uncertainty of the stock market. Kwok and Tadesse (2006) highlight cultural preferences in the development of financial markets or the banking sector. They find that higher UAI cultures tend to favor the development of a bank-based system.

In high UAI cultures, we expect firms to prefer borrowing debt and rather borrow for the short-term than the long-term (Zheng et al., 2012). Inversely firms in lower UAI cultures would be fine borrowing for the long-term despite higher uncertainty in future income to re-pay debt.

Firms in low UAI cultures may also choose to dilute equity through the stock market. This may be conditioned by firms' equity market value (Ferris et al., 2018). It may also be driven by firms' ability to raise the highest financing possible from either debt or equity, as they are less averse to risk-taking. They may choose to do both debt and equity financing at the same time (Myers, 2001).

Therefore, we expect UAI to have a positive relationship with the short-term debt-to-equity ratio. We expect UAI to have a negative relationship with the long-term debt-to-equity ratio. Our hypothesis writes as:

H2c. There is a positive (negative) association between uncertainty avoidance and the shortterm (long-term) debt-to-equity ratios.

\subsubsection{Influence of long-term orientation on capital structure}

Long-term orientation indicates the preference for the future where one expects the most important events to happen (Hofstede, 2001). In long-term orientation cultures (high LTO), people tend to save more now to care for their future, while in short-term oriented cultures (low LTO), people prefer to spend now even if it meant "borrowing" from their future income. Fuchs-Schündeln et al. (2017) find higher household saving rates in long-term oriented cultures, e.g. Japan (LTO index: 88) and South Korea (LTO index: 100), compared with the USA (LTO index: 26).

Chang et al. (2012) find that firms from LTO cultures tend offer or borrow short-term debt. Due to aversion to the future unknown, we expect firms from LTO cultures to anticipate or define risk in order to minimize future uncertainty. Debt raising would tend to offer higher certainty then equity financing. 
Furthermore, short-term debt would reduce future uncertainty than having long-term debt. Therefore, we expect LTO to have a positive relationship with the short-term debt-to-equity ratios. We expect a negative relationship between LTO and long-term debt-to-equity ratios. It leads to our hypothesis as:

H2d. There is a positive (negative) association between long-term orientation and the shortterm (long-term) debt-to-equity ratios.

Our hypotheses are defined. We look to define our empirical strategy in the following section to test these hypotheses.

\section{Variables, data, and methodology}

Our empirical strategy is also grounded on the NIE framework proposed by Williamson's (2000). We consider culture at level-1 and capital structure at level-4. However, we merge level-2 and level-3 into a single set of institutional variables as governance constraints are part of the legal framework of the country. This section present our variables, data set, and methodology.

\subsection{Variables}

All the variables are listed in the table 1.

\subsubsection{Capital structure variables}

The literature in finance generally uses a single measure of capital structure (e.g. Harris \& Raviv, 1991; Rajan \& Zingales, 1995; Campbell \& Rogers, 2018). A single measure is also used in the existing literature about culture and capital structure (Chui et al., 2002; Fauver \& McDonald, 2015).

However, we choose to use four variables of capital structure that are the ratios of short-term and longterm debt to the market and book values of equity (Titman \& Wessels, 1988). Our choice of four measures allows us to analyze in-depth the influence of culture on two time horizons of debt and two value measures of equity. On the one hand, the choice of these various metrics is based on the fact that culture has an influence on debt maturity (Zheng et al., 2012; Chang et al., 2012). On the other hand, it is based on the market timing issue raised by Ferris et al. (2018). We expect our detailed measures to unravel a closer insight of culture's influence on firms' leverage choices.

\subsubsection{National culture}

The variables are the four following cultural dimensions from Hofstede (2001) as individualism versus collectivism (IDV), masculinity versus feminity (MAS), uncertainty avoidance (UAI), long-term versus short-term orientation (LTO). We exclude the remaining two dimensions of PDI and IVR, due to their high correlation with the four selected. The strengths of Hofstede's $(1980,2001)$ cultural dimensions are that they have been developed from a large countries sample and have been further cross validated by third party studies (Hofstede et al., 2010). 
We assume the stability of culture over the entire period (Williamson, 2000; Hofstede, 1980, 2001). Therefore, any changes that might have occurred in the cultural dimensions scores over the period of our study could produce an undetected impact on our measures of culture's influence on capital structure choices.

\subsubsection{Firm-level variables}

Our four firm-level control variables are the financial measures of capital expenditure over total assets to represent the financial outflows for which the firm needs to raise financing through debt or equity (Myers, 1984; Frank \& Goyal, 2009). The variable of profitability is taken as the operating income before tax over total assets as the previous period income affects retained earnings and therefore the current capital structure (Frank \& Goyal, 2009; Fan et al., 2012). Firm size variables is its total sales as size affects the cost of debt financing (Rajan \& Zingales, 1995; Ferris et al., 2018). Firm's growth variable is the total asset growth (Titman \& Wessels, 1988). 
Table 1: Summary of Variables.

\begin{tabular}{|c|c|c|c|}
\hline Variables & Descriptions & @Time & Sources \\
\hline \multicolumn{4}{|c|}{ Dependent variables: measures of Capital structure } \\
\hline STD2MVE & Short Term Debt divided by Market Value of Equity & $\mathrm{t}$ & Titmman \& Wessels (1988) \\
\hline STD2BVE & Short Term Debt divided by Book Value of Equity & $\mathrm{t}$ & Titmman \& Wessels (1988) \\
\hline LTD2MVE & Long Term Debt divided by Market Value of Equity & $\mathrm{t}$ & Titmman \& Wessels (1988) \\
\hline LTD2BVE & Long Term Debt divided by Book Value of Equity & $\mathrm{t}$ & Titmman \& Wessels (1988) \\
\hline \multicolumn{4}{|c|}{ Explanatory variables: Hofstede's cultural dimensions } \\
\hline IDV & Individualism vs. Collectivism & $\mathrm{t}$ & Hofstede $(1980,2001,2010)$ \\
\hline MAS & Masculinity vs. Feminity & $\mathrm{t}$ & Hofstede $(1980,2001,2010)$ \\
\hline UAI & Low-High Uncertainty Avoidance & $\mathrm{t}$ & Hofstede $(1980,2001,2010)$ \\
\hline LTO & Long Term vs. Short Term Orientation & $\mathrm{t}$ & Hofstede $(2001,2010)$ \\
\hline \multicolumn{4}{|l|}{ Firm-level control variables } \\
\hline Capex Expenditure/Total Assets & Proxy for firm's investment & $\mathrm{t}-1$ & Titmman \& Wessels (1988) \\
\hline Operating Income/Total Asset & Firm's Profitability Indicator & $\mathrm{t}-1$ & Titmman \& Wessels (1988) \\
\hline Total Sales (log) & Firm's Size measured by its Total Sales & $\mathrm{t}-1$ & Titmman \& Wessels (1988) \\
\hline Asset growth & Assets Growth Rate from $t$ to $t+1$ & $\mathrm{t}+1$ & Titmman \& Wessels (1988) \\
\hline SIC Industry Sector & Industry sector of the Firm as SIC code level 1 & $\mathrm{t}$ & $\begin{array}{l}\text { Bradley et al.(1984); } \\
\text { Harris \& Raviv (1991) }\end{array}$ \\
\hline \multicolumn{4}{|l|}{$\underline{\text { Country-level control variables }}$} \\
\hline GDP per Capita $(\log )$ & Measure of Country's wealth & $\mathrm{t}$ & $\begin{array}{l}\text { World Bank Development } \\
\text { Indicator (2018) }\end{array}$ \\
\hline Banking sector development (log) & Domestic Credit to Private Sector (as \% of GDP ) & $\mathrm{t}$ & $\begin{array}{l}\text { World Bank Development } \\
\text { Indicator (2018) }\end{array}$ \\
\hline Stock market development $(\log )$ & Stock market capitalization (as \% of GDP ) & $\mathrm{t}$ & $\begin{array}{l}\text { World Bank Development } \\
\text { Indicator (2018) }\end{array}$ \\
\hline Law-WJP & Rule of Law - World Justice Projet & $\mathrm{t}$ & Botero \& Ponce (2011) \\
\hline \multicolumn{4}{|l|}{$\underline{\text { Robusteness test variables }}$} \\
\hline Collateral value & ((Tangible Assets + Intangible Assets)/ Total Assets) & $\mathrm{t}-1$ & Titmman \& Wessels (1988) \\
\hline Agency Cost & $\begin{array}{l}((\text { R\&D Expenses / Total Sales })+(\text { Sales \& Marketing } \\
\text { expenses/Total Sales }))\end{array}$ & $\mathrm{t}-1$ & $\begin{array}{l}\text { Bradely et al.(1984) } \\
\text { Rajan \& Zingales (1995) }\end{array}$ \\
\hline CRI & Creditor Rights Index & $\mathrm{t}$ & Djankov et al. (2007) \\
\hline LRI & Legal Rights Index & $\mathrm{t}$ & $\begin{array}{l}\text { World Bank Development } \\
\text { Indicator (2018) }\end{array}$ \\
\hline
\end{tabular}

Dependent and key variables for measures of firms' financials, country's economic development, and institutional development.

\subsubsection{Country-level variables}

Each institution in the country plays a role on firm's choice of debt and equity (Shleifer \& Vishny, 1997; Demirgüç-Kunt \& Maksimovic, 1998; Myers, 2001). We represent these institutions by four countrylevel control variables.

The development of banking sector and stock markets are represented by the variables of total credit to private sector over GDP and country's stock market capitalization over GDP (Rajan \& Zingales, 1995; 
Li et al., 2013). The rule of law measure from the World Justice Project ${ }^{6}$ (Botero \& Ponce, 2011), as the implementation of law is important for creditors and investors protection (Shleifer \& Vishny, 1997). Furthermore, we use the country GDP per capita as country's wealth is said to be correlated with some of national culture dimensions (Hofstede, 1980, 2001).

\subsection{Data}

Our dataset contains firm observations. We consider the following industry sectors based on the SIC level 1 sectors: mining \& construction (1000-1799), manufacturing (2000-3999), utilities (4000-4999), wholesale \& retail trade (5000-5999), and services (7000-8999). Financial sector firms are excluded (6000-6799).

Firms' financial data is computed from Reuters Datastream database. Country's institutional data is extracted from the World Bank Indicator database ${ }^{7}$ and the cultural dimensions data is obtained from Hofstede ${ }^{8}$ index.

Our initial sample consists of 18,001 firms from 68 countries, with cross-sectional data over the 20092017 period. We only keep countries with at least 15 firms in an industry sector accounting for sample design with clustered data constraints (Hancock et al., 2010). To avoid for single-year abnormal data (Titman \& Wessels, 1988), each data point is computed as the simple average of three consecutive years' data-points 9 . Firms' financials and country's institutional data is considered within three periods of 2009-2011 $(t-1), 2012-2014(t)$, and 2015-2017(t+1). On the resulting dataset, we apply trimming on both side of the dependent variable's data distribution tails to remove outliers through the classic rule of thumb method ${ }^{10}$ (Navidi, 2008). After data treatment, our financial dataset is made of 5,968 firms spread across 33 countries (see table 2).

\footnotetext{
${ }^{6} \mathrm{https} / / /$ worldjusticeproject.org/our-work/wjp-rule-law-index/wjp-rule-law-index-2017-2018

${ }^{7}$ World Bank Database: https://data.worldbank.org/indicator

${ }^{8}$ The dimensions index is referred to as VSM100 dated 8dec2015: https://geerthofstede.com/research-and-vsm/dimension-data-matrix/

${ }^{9}$ In case of a single year missing point in a period, we complete it by the period's mean value if the difference between the two data-points is below $10 \%$

${ }^{10}$ We perform a "Right-tail" trimming for values below $\left(\mathrm{Q}_{1}-3 \times\left(\mathrm{Q}_{3}-\mathrm{Q}_{1}\right)\right)$ and "left-tail" trimming for values above $\left(\mathrm{Q}_{3}+3 \times\left(\mathrm{Q}_{3}-\mathrm{Q}_{1}\right)\right)$; where $\left(\mathrm{Q}_{3}-\mathrm{Q}_{1}\right)$ is the interquartile range.
} 
Table 2: Descriptive statistics.

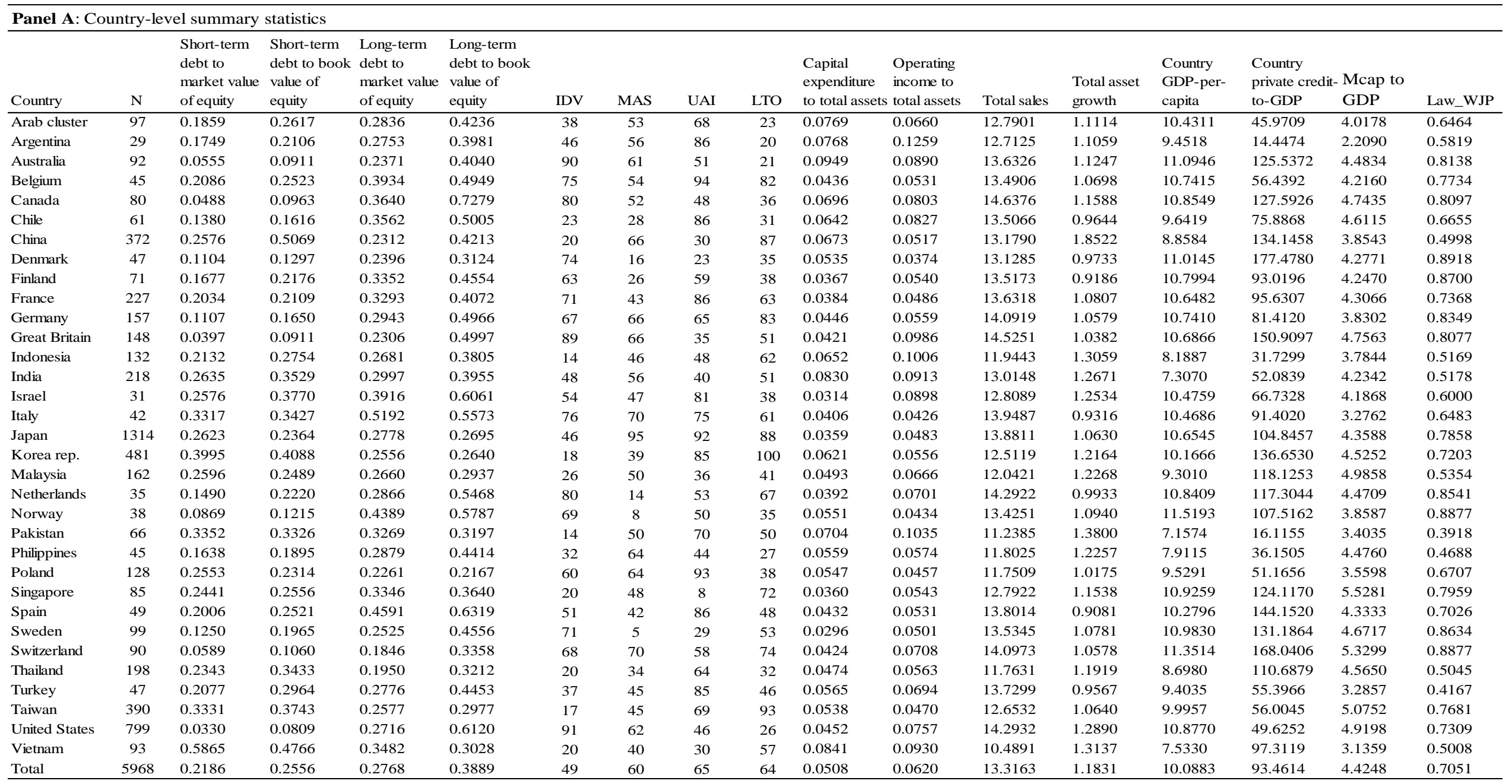

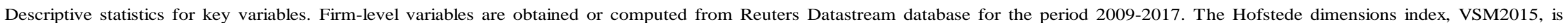

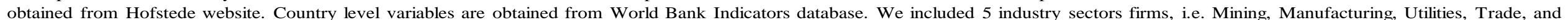

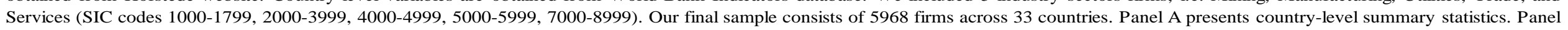
B presents firm-level summary statistics. Panel C presents the pearson correlation matrix using firm-level observations. 


\begin{tabular}{|c|c|c|c|c|c|c|}
\hline \multicolumn{7}{|l|}{ Panel B: Firm-level summary statistics } \\
\hline & Mean & StdDev & 5th Percentile & Median & 95th Percentile & $\mathrm{N}$ \\
\hline Short term debt to market value of equity & 0.2186 & 0.2853 & 0.0022 & 0.1024 & 0.8622 & 5968 \\
\hline Short term debt to book value of equity & 0.2556 & 0.2815 & 0.0048 & 0.1561 & 0.8843 & 5968 \\
\hline Long term debt to market value of equity & 0.2768 & 0.3055 & 0.0036 & 0.1714 & 0.9304 & 5968 \\
\hline Long term debt to book value of equity & 0.3889 & 0.3971 & 0.0061 & 0.2640 & 1.2227 & 5968 \\
\hline Capital expenditure to total assets & 0.0508 & 0.0483 & 0.0052 & 0.0383 & 0.1373 & 5968 \\
\hline Operating income to total assets & 0.0620 & 0.0798 & -0.0247 & 0.0579 & 0.1777 & 5968 \\
\hline Total sales $(\log )$ & 13.3163 & 1.9234 & 10.2681 & 13.2486 & 16.5980 & 5968 \\
\hline Total assets growth & 1.1831 & 1.5162 & 0.7096 & 1.0531 & 1.8082 & 5968 \\
\hline GDP per capita (log) & 10.0883 & 1.0403 & 7.5330 & 10.6545 & 10.9830 & 5968 \\
\hline Country private credit (log) & 4.4399 & 0.4764 & 3.6959 & 4.6525 & 4.9709 & 5968 \\
\hline Country market capitalization $(\log )$ & 4.4248 & 0.5009 & 3.5598 & 4.3588 & 5.0752 & 5968 \\
\hline Law_WJP & 0.7051 & 0.1215 & 0.4998 & 0.7309 & 0.8634 & 5968 \\
\hline
\end{tabular}

Panel C: Correlation matrix using firm-level observations

\begin{tabular}{|c|c|c|c|c|c|c|c|c|c|c|c|c|c|c|c|c|}
\hline & $\begin{array}{l}\text { Short-term } \\
\text { debt to } \\
\text { market value } \\
\text { of equity }\end{array}$ & $\begin{array}{l}\text { Short-term } \\
\text { debt to } \\
\text { book value } \\
\text { of equity }\end{array}$ & $\begin{array}{l}\text { Long-term } \\
\text { debt to } \\
\text { market value } \\
\text { of equity }\end{array}$ & $\begin{array}{l}\text { Long-term } \\
\text { debt to } \\
\text { book value } \\
\text { of equity }\end{array}$ & Individualism & Masculinity & $\begin{array}{l}\text { Uncertainty } \\
\text { avoidance }\end{array}$ & $\begin{array}{l}\text { Long term } \\
\text { orientation }\end{array}$ & $\begin{array}{l}\text { Capital } \\
\text { expenditure } \\
\text { to total } \\
\text { assets } \\
\end{array}$ & $\begin{array}{l}\text { Operating } \\
\text { income to } \\
\text { total assets }\end{array}$ & Total sales & $\begin{array}{l}\text { Total asset } \\
\text { growth }\end{array}$ & $\begin{array}{l}\text { Country } \\
\text { GDP per } \\
\text { capita } \\
\end{array}$ & $\begin{array}{l}\text { Country } \\
\text { private } \\
\text { credit }\end{array}$ & $\begin{array}{l}\text { Country } \\
\text { market cap. }\end{array}$ & Law_WJP \\
\hline STD2MVE & 1 & & & & & & & & & & & & & & & \\
\hline STD2BVE & $0.775^{* * *}$ & 1 & & & & & & & & & & & & & & \\
\hline LTD2MVE & $0.404 * * *$ & $0.260 * * *$ & 1 & & & & & & & & & & & & & \\
\hline LTD2BVE & $0.0712 * * *$ & $0.211^{* * * *}$ & $0.713^{* * * *}$ & 1 & & & & & & & & & & & & \\
\hline Individualism & $-0.342^{* * * *}$ & $-0.372 * * *$ & $0.0256^{*}$ & $0.223 * * *$ & 1 & & & & & & & & & & & \\
\hline Masculinity & -0.0112 & $-0.0758^{* * *}$ & -0.0119 & $-0.0803^{* * *}$ & $0.132^{* * * *}$ & 1 & & & & & & & & & & \\
\hline Uncertainty avoidance & $0.150^{* * *}$ & 0.0167 & 0.0193 & $-0.171 * * *$ & $-0.154^{* * *}$ & $0.408 * * *$ & 1 & & & & & & & & & \\
\hline Long term orientation & $0.277^{* * * *}$ & $0.254^{* * *}$ & -0.0151 & $-0.216^{* * *}$ & $-0.570 * * *$ & $0.322 * * *$ & $0.466^{* * *}$ & 1 & & & & & & & & \\
\hline Capital expenditure to total assets & -0.0187 & $0.0473 * * *$ & $0.0969^{* * *}$ & $0.132 * * *$ & $-0.0964 * * *$ & $-0.115 * * *$ & $-0.112^{* * *}$ & $-0.0506^{* * *}$ & 1 & & & & & & & \\
\hline Operating income to total assets & $-0.182 * * *$ & $-0.151 * * *$ & $-0.150 * * *$ & $-0.0320^{*}$ & $0.0562 * * *$ & $-0.0438 * * *$ & $-0.101 * * *$ & $-0.124 * * *$ & $0.159 * * *$ & 1 & & & & & & \\
\hline Total sales (log) & $-0.0925 * * *$ & $-0.0887 * * *$ & $0.173 * * *$ & $0.257 * * *$ & $0.343^{* * *}$ & $0.215^{* * * *}$ & $0.0347^{* *}$ & $-0.0303^{*}$ & $-0.0339 * *$ & $0.212 * * *$ & 1 & & & & & \\
\hline Total asset growth & -0.0242 & $0.0409^{* *}$ & $-0.0411^{* *}$ & 0.00895 & $-0.0296^{*}$ & -0.00680 & $-0.0742^{* * *}$ & -0.000293 & -0.000208 & -0.0246 & $-0.0721^{* * *}$ & 1 & & & & \\
\hline Country GDP per capita (log) & $-0.189 * * *$ & $-0.272 * * *$ & 0.0120 & $0.0687 * * *$ & $0.571^{* * *}$ & $0.229 * * *$ & $0.284 * * *$ & $0.0351^{* *}$ & $-0.199 * * *$ & $-0.0763 * * *$ & $0.332 * * *$ & $-0.0610^{* * *}$ & 1 & & & \\
\hline Country private credit (log) & $0.0882^{* * *}$ & $0.0932 * * *$ & -0.0223 & $-0.0994 * * *$ & $-0.139 * * *$ & $0.0644 * * *$ & $0.0646^{* * *}$ & $0.440^{* * * *}$ & $-0.0630 * * *$ & $-0.1000 * * *$ & $0.0598^{* * *}$ & -0.00123 & $0.279^{* * *}$ & 1 & & \\
\hline Country market capitalization (log) & $-0.136 * * *$ & $-0.160 * * *$ & $-0.0339 * *$ & $0.0574 * * *$ & $0.212^{* * *}$ & $-0.0766^{* * *}$ & $-0.167 * * *$ & $-0.0803^{* * *}$ & $-0.104 * * *$ & -0.0174 & $0.142 * * *$ & -0.0242 & $0.451^{* * *}$ & $0.119^{* * *}$ & 1 & \\
\hline Law_WJP & $-0.121 * * *$ & $-0.235^{* * * *}$ & 0.0135 & 0.00683 & $0.472^{* * * *}$ & $0.204 * * *$ & $0.327 * * *$ & $0.206^{* * * *}$ & $-0.177 * * *$ & $-0.0758 * * *$ & $0.287 * * *$ & $-0.0828 * * *$ & $0.883^{* * *}$ & $0.291 * * *$ & $0.437 * * *$ & 1 \\
\hline
\end{tabular}


At the country-level, Israel has the lowest number of firms (31) and Japan the highest (1314). USA has the lowest average ratios of short-term debt to market (0.0330) or book (0.0809) value of equity. It may suggest that USA (LTO: 26) firms do not take much short-term external finance or that their equity values are high. Vietnam has the highest short-term debt to market (0.5865) and China the highest shortterm debt to book (0.5069). Vietnamese (LTO: 57) and Chinese (LTO: 87) firms seems to externally finance more of their short-term debt. Chile has the lowest long-term debt to market (0.1846) and Poland the lowest long-term debt to book (0.2167). Chilean and Poland firms may have higher earning to internally finance their growth. Italy has the highest long-term debt to market (0.5192) and Canada the highest long-term debt to book (0.7279). Italy (IDV: 76) and Canada (IDV: 80) firm take the most longterm debt in their leverage ratio.

At the firm-level, short-term debt to market value of equity mean is 0.2186 . Twenty of 33 countries' mean is above. Short-term debt to book value of equity mean is 0.2556 . Twenty of 33 countries' mean is above. Long-term debt to market value of equity mean is 0.2768 . Fourteen of 33 countries mean is above. Long-term debt to book value of equity mean is 0.3889 . Twelve of 33 countries mean is above. This data analysis suggests a disparity between firms short-term and long-term debt-to-equity.

The correlation matrix shows the cultural dimensions to be mostly correlated with the debt-to-equity ratios. Our firm-level financial variables of growth, profitability, and size present significant correlation with our dependent variables. Our country-level institutional variables present significant correlation with our dependent variables, except with the long-term debt to market value of equity. In the latter, only the stock market development variable is correlated.

\subsection{Methodology}

We adopt Titman and Wessels (1988) empirical test methodology of capital structure as follows. We use a nine-year period of 2009-2017 that is split into three consecutive periods of three years each. We consider the periods 2009-2011 as $t-1,2012-2014$ as $t$, and 2015-2017 as $t+1$. Titman and Wessels describe at time $t$, firms base their capital structure decisions on their previous period $t-1$ results, and deploy their financing for firm's growth from time $t$ to $t+1$.

At time $t$ are our dependent variables of capital structure, along with country-level variables of national culture and economic development. We control for lagged firm-level variables at time $t-1$ for capital expenditure, operating profit, and sales. For lagged variable at $t+1$ of firm's asset growth. We represent firm's industry sector by an industry dummy variable representing five SIC level-1 industry sectors of mining, manufacturing, utilities, trade, and services.

Therefore, for each of our four measures of capital structure with firm $i$, industry sector $k$, country $j$, and time $t$, our empirical model (see equation. 1) writes as: 


$$
\begin{aligned}
Y_{i, k, j, t}=\alpha_{0}+\alpha_{1} \text { Culture }_{j} & +\alpha_{2} \text { Firm }_{\text {level }} \text { Control Variables }_{i, k, j, t-1} \\
& +\alpha_{3} \text { Firm }_{\text {level }} \text { Control Variables }_{i, k, j, t+1} \\
& +\alpha_{4} \text { Country }_{\text {level }} \text { Control Variables } \text { Son }_{j, t}+\text { Industry }_{k, t} \\
& +\varepsilon_{k, j, t}
\end{aligned}
$$

Our core hypotheses $\mathrm{H} 1$ will be rejected if the coefficients of culture are not significant. Our secondary hypothesis (H2a to $\mathrm{H} 2 \mathrm{~d})$ focus on the signs of coefficients.

\section{Results and comments}

\subsection{Baseline model results}

Our first result is that culture influences both short-term and long-term capital structures choices (see table 3). Culture significance is higher for the short-term debt-to-equity ratios than the long-term ones. It is higher for the short-term debt to equity market than book value. On the opposite, it is higher for the long-term debt to equity book for than market value. Furthermore, culture dimensions relationship signs differ between short-term and long-term ratios. These results may be in line with the pecking order theory as firm first maximize their debt levels while timing it on the value of their equity.

In accordance with our hypotheses, these findings clearly indicate that culture influences differently the short-term and the long-term capital structures. Culture's influence is also different whether the ratios are with the book value or market value of equity. We are going to discuss these findings in details later.

The first level of analysis highlights multiple findings. First, it shows new evidence that culture influences firms' choices of short-term and long-term capital structures, adding new knowledge to the literature (Chui et al., 2002; Fauver \& McDonald, 2015). Second, our results show culture as a determinant of firms' capital structure choice in raising debt financing against equity book or market value (Ferris et al., 2018). Third, it indirectly confirms that the maturity of debt on firms' balance sheet is influenced by culture (Chang et al., 2012; Zheng et al., 2012).

Our first key contribution is that it is meaningful to dissociate capital structure into both short-term and long-term leverage ratios because culture influences differently each one of them. The second key contribution brought the new insight of culture's differing influence on the leverage ratios based on book or market value of equity. These two key findings underlines that firms debt-to-equity choices, highlighted in the financial literature (Titman \& Wessels, 1988; Ferris et al., 2018), are influenced by their country-of-origin cultural values. Our paper is the first to present such results contributing to add to the body-of knowledge in culture and capital structure (Chui et al., 2002; Fauver \& McDonald, 2015). 
Table 3: Culture influence on capital structure at firm-level. Baseline model.

\begin{tabular}{|c|c|c|c|c|c|c|c|c|c|c|c|c|}
\hline & $\begin{array}{l}\text { Short-term } \\
\text { debt to market } \\
\text { value of equity } \\
\text { (1) } \\
\end{array}$ & $\begin{array}{l}\text { Short-term } \\
\text { debt to market } \\
\text { value of equity } \\
\quad(2) \\
\end{array}$ & 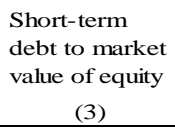 & \begin{tabular}{|l}
$\begin{array}{l}\text { Short-term } \\
\text { debt to book } \\
\text { value of equity } \\
\text { (4) }\end{array}$ \\
\end{tabular} & $\begin{array}{l}\begin{array}{l}\text { Short-term } \\
\text { debt to book } \\
\text { value of equity } \\
(5)\end{array} \\
\end{array}$ & $\begin{array}{l}\begin{array}{l}\text { Short-term } \\
\text { debt to book } \\
\text { value of equity } \\
(6)\end{array} \\
\end{array}$ & \begin{tabular}{|l}
$\begin{array}{l}\text { Long-term } \\
\text { debt to market } \\
\text { value of equity } \\
\text { (7) }\end{array}$ \\
\end{tabular} & $\begin{array}{l}\text { Long-term } \\
\text { debt to market } \\
\text { value of equity } \\
\quad(8) \\
\end{array}$ & $\begin{array}{l}\text { Long-term } \\
\text { debt to market } \\
\text { value of equity } \\
(9) \\
\end{array}$ & \begin{tabular}{|c|}
$\begin{array}{l}\text { Long-term } \\
\text { debt to book } \\
\text { value of equity } \\
(10)\end{array}$ \\
\end{tabular} & $\begin{array}{l}\text { Long-term } \\
\text { debt to book } \\
\text { value of equity } \\
\quad(11) \\
\end{array}$ & $\begin{array}{l}\text { Long-term } \\
\text { debt to book } \\
\text { value of equity } \\
\quad(12) \\
\end{array}$ \\
\hline \multicolumn{13}{|c|}{ Hofstede Cultural Dimensions } \\
\hline Individualism & $\begin{array}{c}-0.0027 * * * \\
(-15.5741)\end{array}$ & & $\begin{array}{c}-0.0018 * * * \\
(-6.4669)\end{array}$ & $\begin{array}{c}-0.0031 * * * \\
(-18.2317)\end{array}$ & & $\begin{array}{c}-0.0012 * * * \\
(-4.3662)\end{array}$ & $\begin{array}{c}0.0007 * * * \\
(3.7992)\end{array}$ & & $\begin{array}{c}-0.0001 \\
(-0.4786)\end{array}$ & $\begin{array}{c}0.0031 * * * \\
(12.8164)\end{array}$ & & $\begin{array}{c}0.0025 * * * \\
(6.5378)\end{array}$ \\
\hline Masculinity & $\begin{array}{c}-0.0006 * * * * \\
(-3.3814)\end{array}$ & & $\begin{array}{c}-0.0008 * * * \\
(-4.2211)\end{array}$ & $\begin{array}{c}-0.0007 * * * * \\
(-3.8641)\end{array}$ & & $\begin{array}{c}-0.0014 * * * * \\
(-7.5766)\end{array}$ & $\begin{array}{c}-0.0007 * * * \\
(-3.4505)\end{array}$ & & $\begin{array}{c}-0.0009 * * * \\
(-4.3917)\end{array}$ & $\begin{array}{c}-0.0012 * * * \\
(-4.5696)\end{array}$ & & $\begin{array}{c}-0.0020 * * * \\
(-7.7485)\end{array}$ \\
\hline Uncertainty Avoidance & $\begin{array}{c}0.0010 * * * \\
(5.6479)\end{array}$ & & $\begin{array}{c}0.0012 * * * \\
(5.9932)\end{array}$ & $\begin{array}{c}-0.0008 * * * * \\
(-4.9143)\end{array}$ & & $\begin{array}{c}-0.0003 \\
(-1.3376)\end{array}$ & $\begin{array}{c}0.0009 * * * \\
(4.6837)\end{array}$ & & $\begin{array}{c}0.0007 * * * * \\
(3.3288)\end{array}$ & $\begin{array}{c}-0.0012 * * * \\
(-5.0691)\end{array}$ & & $\begin{array}{c}-0.0011 * * * \\
(-4.1472)\end{array}$ \\
\hline Long term Orientation & $\begin{array}{c}0.0010 * * * * \\
(5.5303)\end{array}$ & & $\begin{array}{c}0.0010 * * * \\
(4.0264)\end{array}$ & $\begin{array}{c}0.0013 * * * \\
(7.0871)\end{array}$ & & $\begin{array}{c}0.0024 * * * * \\
(9.4492)\end{array}$ & $\begin{array}{c}0.0004 * * \\
(2.0201)\end{array}$ & & $\begin{array}{c}-0.0001 \\
(-0.3065)\end{array}$ & $\begin{array}{c}-0.0001 \\
(-0.4040)\end{array}$ & & $\begin{array}{c}0.0007 * * * \\
(2.0231)\end{array}$ \\
\hline \multicolumn{13}{|l|}{ Firm-Level Variables } \\
\hline CAPEX / TA & & $\begin{array}{c}-0.1588 * * \\
(-2.1226)\end{array}$ & $\begin{array}{l}-0.1320^{*} \\
(-1.8187)\end{array}$ & & $\begin{array}{l}0.1497 * * \\
(2.0582)\end{array}$ & $\begin{array}{c}0.1448 * * \\
(2.0512)\end{array}$ & & $\begin{array}{c}0.6483 * * * \\
(8.1463)\end{array}$ & $\begin{array}{c}0.6362 * * * \\
(7.9919)\end{array}$ & & $\begin{array}{l}1.1027 * * * \\
(10.9641)\end{array}$ & $\begin{array}{l}1.0186^{* * * *} \\
(10.2976)\end{array}$ \\
\hline $\mathrm{EBIT} / \mathrm{TA}$ & & $\begin{array}{c}-0.6457 * * * \\
(-14.1405)\end{array}$ & $\begin{array}{c}-0.5935 * * * \\
(-13.3781)\end{array}$ & & $\begin{array}{c}-0.6034 * * * \\
(-13.5878)\end{array}$ & $\begin{array}{c}-0.5602 * * * \\
(-12.9827)\end{array}$ & & $\begin{array}{c}-0.8425 * * * \\
(-17.3436)\end{array}$ & $\begin{array}{c}-0.8452 * * * \\
(-17.3699)\end{array}$ & & $\begin{array}{c}-0.6189 * * * * \\
(-10.0808)\end{array}$ & $\begin{array}{c}-0.6803 * * * \\
(-11.2524)\end{array}$ \\
\hline SALES $(\log )$ & & $\begin{array}{c}0.0008 \\
(0.3998)\end{array}$ & $\begin{array}{c}0.0075 * * * \\
(3.6933)\end{array}$ & & $\begin{array}{c}0.0066^{* * * * * *} \\
(3.3838)\end{array}$ & $\begin{array}{c}0.0123 * * * * \\
(6.2413)\end{array}$ & & $\begin{array}{c}0.0348 * * * * \\
(16.2441)\end{array}$ & $\begin{array}{l}0.0374 * * * * \\
(16.8343)\end{array}$ & & $\begin{array}{l}0.0562 * * * \\
(20.7508)\end{array}$ & $\begin{array}{l}0.0539^{* * * * *} \\
(19.4909)\end{array}$ \\
\hline TA Growth & & $\begin{array}{c}-0.0066 * * * * \\
(-2.8609)\end{array}$ & $\begin{array}{c}-0.0054 * * \\
(-2.4141)\end{array}$ & & $\begin{array}{l}0.0040^{*} \\
(1.7947)\end{array}$ & $\begin{array}{l}0.0037^{*} \\
(1.7111)\end{array}$ & & $\begin{array}{c}-0.0070^{* * * * *} \\
(-2.8623)\end{array}$ & $\begin{array}{c}-0.0062 * * \\
(-2.5295)\end{array}$ & & $\begin{array}{c}0.0046 \\
(1.5067)\end{array}$ & $\begin{array}{c}0.0034 \\
(1.1360)\end{array}$ \\
\hline \multicolumn{13}{|l|}{ Country-Level Variables } \\
\hline GDP per Capita (log) & & $\begin{array}{c}-0.0973 * * * \\
(-13.1908)\end{array}$ & $\begin{array}{c}-0.0487 * * * \\
(-5.9851)\end{array}$ & & $\begin{array}{c}-0.0789 * * * \\
(-11.0013)\end{array}$ & $\begin{array}{c}-0.0117 \\
(-1.4825)\end{array}$ & & $\begin{array}{c}-0.0248^{* * *} * \\
(-3.1605)\end{array}$ & $\begin{array}{c}-0.0216 * * \\
(-2.4235)\end{array}$ & & $\begin{array}{c}0.0604 * * * \\
(6.0885)\end{array}$ & $\begin{array}{c}0.0420^{* * * *} \\
(3.7846)\end{array}$ \\
\hline Pvt. Credit to GDP (log) & & $\begin{array}{c}0.0745^{* * * * *} \\
(9.7494)\end{array}$ & $\begin{array}{c}0.0203 * * \\
(2.3274)\end{array}$ & & $\begin{array}{c}0.0986 * * * * \\
(13.2741)\end{array}$ & $\begin{array}{l}0.0200^{* * * *} \\
(2.3594)\end{array}$ & & $\begin{array}{c}-0.0247^{* * * * *} \\
(-3.0427)\end{array}$ & $\begin{array}{c}-0.0239 * * \\
(-2.4929)\end{array}$ & & $\begin{array}{c}-0.0950 \text { ***** } \\
(-9.2525)\end{array}$ & $\begin{array}{c}-0.0715^{* * * *} \\
(-6.0092)\end{array}$ \\
\hline Market Cap. To GDP (log) & & $\begin{array}{c}-0.0387 * * * \\
(-4.9849)\end{array}$ & $\begin{array}{c}-0.0213 * * \\
(-2.4817)\end{array}$ & & $\begin{array}{c}-0.0230 * * * * \\
(-3.0409)\end{array}$ & $\begin{array}{c}-0.0262 * * * \\
(-3.1370)\end{array}$ & & $\begin{array}{c}-0.0243 * * * \\
(-2.9360)\end{array}$ & $\begin{array}{c}-0.0211 * * \\
(-2.2478)\end{array}$ & & $\begin{array}{c}0.0417 * * * \\
(3.9940)\end{array}$ & $\begin{array}{c}0.0132 \\
(1.1256)\end{array}$ \\
\hline Law_wjp & & $\begin{array}{c}0.3880 * * * * \\
(6.2763)\end{array}$ & $\begin{array}{l}0.1227^{*} \\
(1.7195)\end{array}$ & & $\begin{array}{c}-0.0704 \\
(-1.1705)\end{array}$ & $\begin{array}{c}-0.4222 * * * \\
(-6.0833)\end{array}$ & & $\begin{array}{c}0.1996 * * * \\
(3.0350)\end{array}$ & $\begin{array}{c}0.1647 * * \\
(2.1049)\end{array}$ & & $\begin{array}{c}-0.5335 * * * * \\
(-6.4188)\end{array}$ & $\begin{array}{c}-0.5145 * * * \\
(-5.2909)\end{array}$ \\
\hline Industry Dummy & $\mathrm{Y}$ & $\mathrm{Y}$ & $\mathrm{Y}$ & $\mathrm{Y}$ & $\mathrm{Y}$ & $\mathrm{Y}$ & $\mathrm{Y}$ & $\mathrm{Y}$ & $\mathrm{Y}$ & $\mathrm{Y}$ & $\mathrm{Y}$ & Y \\
\hline Constant & $\begin{array}{c}0.1851 * * * * \\
(9.5240)\end{array}$ & $\begin{array}{c}0.7244 * * * * \\
(13.0955)\end{array}$ & $\begin{array}{c}0.5057 * * * \\
(9.1490)\end{array}$ & $\begin{array}{l}0.3617 * * * \\
(18.9892)\end{array}$ & $\begin{array}{c}0.6375 * * * \\
(11.8476)\end{array}$ & $\begin{array}{c}0.5246 * * * \\
(9.7584)\end{array}$ & $\begin{array}{c}0.1406 * * * \\
(6.4585)\end{array}$ & $\begin{array}{c}0.1494 * * \\
(2.5377)\end{array}$ & $\begin{array}{l}0.1123^{*} \\
(1.8526)\end{array}$ & $\begin{array}{c}0.3569 * * * \\
(13.1445)\end{array}$ & $\begin{array}{c}-0.3376^{* * * * *} \\
(-4.5395)\end{array}$ & $\begin{array}{c}-0.0923 \\
(-1.2246)\end{array}$ \\
\hline Observations & 5,968 & 5,968 & 5,968 & 5,968 & 5,968 & 5,968 & 5,968 & 5,968 & 5,968 & 5,968 & 5,968 & 5,968 \\
\hline R2 & 0.1463 & 0.1258 & 0.1821 & 0.1583 & 0.1506 & 0.2053 & 0.0670 & 0.1374 & 0.1422 & 0.1405 & 0.1844 & 0.2161 \\
\hline Adjusted R2 & 0.145 & 0.124 & 0.180 & 0.157 & 0.149 & 0.203 & 0.0658 & 0.136 & 0.140 & 0.139 & 0.183 & 0.214 \\
\hline
\end{tabular}

The effects of culture on short-term and long-term debt-to-equity (market value \& book value), at the firm-level. Manufacturing (2000-3999), Utilities (4000-4999), Trade (5000-5999), Services (7000-8999). The estimation includes four cultural dimensions, four firm-level control variables, and four country-level control variables (see table 1). The dependent variables are three years mean over 2012-2014. The firm-level variables are 3 years mean values over 2009-2011, for capital expenditure to total assests, operating income to total assets, and for total sales. For total assets growth, we compute the ratio of total assets mean over 2012-2014 \& 2015-2017. The insitutional variables values are three years mean over $2012-2014$.

t-statistics in parentheses. *** $\mathrm{p}<0.01, * * \mathrm{p}<0.05, * \mathrm{p}<0.1$. 
Culture influences firms' risk-taking through the agency and institutional channels (Li et al., 2013; Pan et al., 2017), which shows in their choices of short-term and long-term debt based on the book or market values of equity. Indeed, culture seems to be influencing firms' choices between debt and equity financing by taking advantage of the higher of their equity book or market value.

It adds the culture determinant to Ferris et al., (2018), who describe that firms do not align their book value to their market value to take advantage of the leverage position based on one ratio or the other. Our findings goes to add the culture determinant to Myers (1984) on firms financing choices through debt or equity. With the above-described results, our hypothesis $\mathbf{H 1}$ stands accepted.

\subsection{Detailed analysis}

Each of the four cultural dimensions share a different relationship sign with the short-term and longterm ratios (see table 3). We find lower individualism, lower masculinity, higher uncertainty avoidance, and higher long-term orientation influence firms choices of short-term debt-to-equity. We find that higher individualism, lower masculinity, lower uncertainty avoidance, and higher long-term orientation influence firms choices of long-term debt-to-equity book value. Only lower masculinity and higher uncertainty avoidance influence firms' long-term debt-to-equity market value.

Our hypothesis H2a is accepted as firms from collectivist cultures (low IDV) takes lower risk, hence prefer to take more STD than LTD (Zheng et al., 2012) irrespective of the equity value. Individualist firms (high IDV) takes on more LTD in regards to their equity book value. However, IDV is not significant for the long-term debt to market value of equity. A possible reason could be that firms' equity book value seems more stable over long periods (Ferris et al., 2018, fig.1, p.545), which could ease firms' ability to raise LTD against it. Furthermore, our results show these firms (see model 9, table 3) have decreasing assets levels, possibly suggesting that these firms maybe selling assets to finance themselves.

Our hypothesis $\mathbf{H 2 b}$ is partially accepted. Masculinity (MAS) shows a negative relationship with the short-term as well as the long-term debt-to-equity. Our result indirectly adds a new contribution to the exiting literature on debt maturity (Zheng et al., 2012; Chang et al., 2012) that finds MAS having a positive relationship with the short-term and negative with the long-term debt. Our hypothesis H2b construction is aligned to that literature. Rather, our results highlight that MAS relationship sign remains negative with both STD and LTD leverage ratios. The coefficient of MAS is lower for the book value of equity ratios than the market value ones, suggesting that firms from more feminine cultures may be taking lower risk by choosing the book value ratio for their financing. Indeed, the book leverage ratio is more stable over long periods (Ferris et al., 2018, fig.1, p.545).

Our hypothesis $\mathbf{H 2 c}$ is accepted. Uncertainty avoidance (UAI) shows a positive relationship with the short-term debt-to-equity market value. UAI is not significant with the short-term debt-to-equity book, 
which may suggest that firms from these cultures choose to raise most of their STD in regards to their equity market value, protecting themselves from the future uncertainty of market value.

UAI shows a positive relationship with the long-term debt-to-equity market value and a negative relationship with the long-term debt-to-equity book value, adding an additional perspective to our hypothesis expectations. Firms from high UAI cultures taking more LTD based on the market value of their equity, may suggest that to prevent from future uncertainty of the market value they take more LTD now.

Our results would add the culture determinant to Ferris et al. (2018) leverage findings in regards to firms aligning their leverage based on the higher of the equity market or book value. Moreover, it indirectly adds to the literature on debt maturity (Zheng et al., 2012; Chang et al., 2012) that finds UAI to share a negative relationship with STD and LTD.

Our hypothesis H2d is accepted. Long-term orientation (LTO) shows a positive relationship with the short-term debt-to-equity. LTO has a significant positive relationship with the long-term debt-to-equity book value and insignificant with the LTD to equity market value. Our results highlight that firms from high LTO cultures prefer to take more STD in regards to equity. Firms from high LTO prefer to take higher LTD only in regards to book value. It could be to avoid the potential risk in the short-term of a higher volatility of equity market vs equity book value (Ferris et al., 2018). Taking on a higher LTD in regards to a higher short-term MVE may jeopardize firms' long-term future. This choice seems aligned with definition of LTO cultures (Hofstede, 2001).

\subsection{Robustness}

We perform multiple robustness tests at the firm-level (see table $4 \& 5$ in subsection 4.3.1), countrylevel (see table $6 \& 7$ in subsection 4.3.2), and sample-level (see table $8 \& 9$ in subsection 4.3.3).

\subsubsection{Firm-level tests}

At the firm-level, we perform two types of tests. First tests are with additional firm financial control variables. The second set of tests check for firms' geographical regions effects.

The first set of firm-level robustness tests (see table 4) check for the effects of agency costs (R\&D and SG\&A expenses) and collateral value of assets (Titman \& Wessels, 1988). Adding these firm-level financial variables does not change the signs and significance levels of our culture dimensions. Indeed, we observe a marginal increase in the value of cultural dimensions coefficients. It suggests that culture has an even higher influence on firms' capital structures choices when we add agency costs and collateral value as determinants. 
Table 4: Firm-level robustness tests with additional financial variables.

\begin{tabular}{|c|c|c|c|c|c|c|c|c|c|c|c|c|c|c|c|c|}
\hline & $\begin{array}{l}\text { Short-term } \\
\text { debt to market } \\
\text { value of equity }\end{array}$ & $\begin{array}{l}\text { Short-term } \\
\text { debt to book } \\
\text { value of equity }\end{array}$ & $\begin{array}{l}\text { Short-term } \\
\text { debt to market } \\
\text { value of equity }\end{array}$ & $\begin{array}{l}\text { Short-term } \\
\text { debt to book } \\
\text { value of equity }\end{array}$ & \begin{tabular}{|l|} 
Short-term \\
debt to market \\
value of equity
\end{tabular} & $\begin{array}{l}\text { Short-term } \\
\text { debt to book } \\
\text { value of equity }\end{array}$ & $\begin{array}{l}\text { Short-term } \\
\text { debt to market } \\
\text { value of equity }\end{array}$ & $\begin{array}{l}\text { Short-term } \\
\text { debt to book } \\
\text { value of equity }\end{array}$ & $\begin{array}{l}\text { Long-term debt } \\
\text { to market value } \\
\text { of equity }\end{array}$ & $\begin{array}{l}\text { Long-term debt } \\
\text { to book value } \\
\text { of equity }\end{array}$ & $\begin{array}{l}\text { Long-term debt I } \\
\text { to market value t } \\
\text { of equity }\end{array}$ & $\begin{array}{l}\text { t Long-term debt } \\
\text { to book value } \\
\text { of equity }\end{array}$ & $\begin{array}{l}\text { Long-term debt } \\
\text { to market value } \\
\text { of equity }\end{array}$ & $\begin{array}{l}\text { Long-term debt } \\
\text { to book value } \\
\text { of equity }\end{array}$ & $\begin{array}{l}\text { Long-term debt } 1 \\
\text { to market value } \\
\text { of equity }\end{array}$ & $\begin{array}{l}\text { Long-term debt } \\
\text { to book value } \\
\text { of equity }\end{array}$ \\
\hline \multicolumn{17}{|l|}{ Hofstede Cultural Dimensions } \\
\hline Individualism & $\begin{array}{c}-0.0017 * * * * \\
(-2.8453)\end{array}$ & $\begin{array}{c}-0.0021 * * * \\
(-5.6969)\end{array}$ & $\begin{array}{c}-0.0020 * * * \\
(-6.2418)\end{array}$ & $\begin{array}{c}-0.0025 * * * \\
(-3.0484)\end{array}$ & $\begin{array}{l}-0.0013 * * \\
(-2.4502)\end{array}$ & $\begin{array}{c}-0.0017 * * * \\
(-4.7307)\end{array}$ & $\begin{array}{c}-0.0015 * * * \\
(-4.6926)\end{array}$ & $\begin{array}{l}-0.0017 * * * \\
(-2.2809)\end{array}$ & $\begin{array}{c}-0.0000 \\
(-0.0328)\end{array}$ & $\begin{array}{l}-0.0007 * \\
(-1.6718)\end{array}$ & $\begin{array}{c}-0.0002 \\
(-0.5692)\end{array}$ & $\begin{array}{c}0.0003 \\
(0.3861)\end{array}$ & $\begin{array}{c}0.0027 * * * \\
(3.5990)\end{array}$ & $\begin{array}{c}0.0029 * * * \\
(5.8307)\end{array}$ & $\begin{array}{c}0.0025 * * * \\
(5.7791)\end{array}$ & $\begin{array}{c}0.0031 * * * \\
(2.9494)\end{array}$ \\
\hline Masculinity & $\begin{array}{l}-0.0007 * * \\
(-2.5424)\end{array}$ & $\begin{array}{l}-0.0007 * * * * \\
(-3.1364)\end{array}$ & $\begin{array}{l}-0.0008 * * * \\
(-3.8513)\end{array}$ & $\begin{array}{l}-0.0007 * * \\
(-2.1275)\end{array}$ & $\begin{array}{l}-0.0015 * * * \\
(-5.7831)\end{array}$ & $\begin{array}{l}-0.0014 * * * * \\
(-6.3410)\end{array}$ & $\begin{array}{l}-0.0013^{* * * *} \\
(-6.6096)\end{array}$ & $\begin{array}{c}-0.0016 * * * \\
(-5.3466)\end{array}$ & $\begin{array}{l}-0.0008^{* * * *} \\
(-2.7151)\end{array}$ & $\begin{array}{l}-0.0007 * * * * \\
(-2.9277)\end{array}$ & $\begin{array}{l}-0.0009 * * * * \\
(-4.1201)\end{array}$ & $\begin{array}{l}-0.0010^{* * * *} \\
(-3.0891)\end{array}$ & $\begin{array}{l}-0.0022 * * * * \\
(-5.9901)\end{array}$ & $\begin{array}{l}-0.0023 * * * \\
(-7.7854)\end{array}$ & $\begin{array}{l}-0.0019 * * * * \\
(-6.9507)\end{array}$ & $\begin{array}{c}-0.0027 * * * * \\
(-6.5482)\end{array}$ \\
\hline Uncertainty Avoidance & $\begin{array}{c}0.0017 * * * * \\
(3.4375)\end{array}$ & $\begin{array}{c}0.0010^{* * *} \\
(4.2784)\end{array}$ & $\begin{array}{l}0.0012 * * * * \\
(5.5799)\end{array}$ & $\begin{array}{l}0.0009 \\
(1.5051)\end{array}$ & $\begin{array}{l}0.0004 \\
(0.8272)\end{array}$ & $\begin{array}{l}-0.0005 * * \\
(-2.2351)\end{array}$ & $\begin{array}{l}-0.0004^{* * *} \\
(-2.0167)\end{array}$ & $\begin{array}{c}-0.0001 \\
(-0.1835)\end{array}$ & $\begin{array}{l}0.0013 * * \\
(2.5484)\end{array}$ & $\begin{array}{l}0.0004 * \\
(1.8072)\end{array}$ & $\begin{array}{c}0.0008^{* * *} \\
(3.2436)\end{array}$ & $\begin{array}{l}0.0014 * * \\
(2.2836)\end{array}$ & $\begin{array}{c}-0.0009 \\
(-1.4456)\end{array}$ & $\begin{array}{c}-0.0010^{* * *} \\
(-3.3569)\end{array}$ & $\begin{array}{l}-0.0012^{* * * *} \\
(-4.2156)\end{array}$ & $\begin{array}{c}-0.0002 \\
(-0.2341)\end{array}$ \\
\hline Long term Orientation & $\begin{array}{c}0.0008 \\
(1.3093)\end{array}$ & $\begin{array}{c}0.0008^{* * * * *} \\
(2.5852)\end{array}$ & $\begin{array}{c}0.0009 * * * * \\
(3.1801)\end{array}$ & $\begin{array}{l}0.0012 * \\
(1.7354)\end{array}$ & $\begin{array}{c}0.0016^{* * * * *} \\
(2.7289)\end{array}$ & $\begin{array}{c}0.0022 * * * * \\
(7.6259)\end{array}$ & $\begin{array}{c}0.0023^{* * * * *} \\
(8.1609)\end{array}$ & $\begin{array}{c}0.0020^{* * * *} \\
(2.8990)\end{array}$ & $\begin{array}{c}-0.0005 \\
(-0.8206)\end{array}$ & $\begin{array}{c}-0.0003 \\
(-1.0889)\end{array}$ & $\begin{array}{c}-0.0003 \\
(-0.8960)\end{array}$ & $\begin{array}{c}-0.0001 \\
(-0.1381)\end{array}$ & $\begin{array}{c}0.0003 \\
(0.4142)\end{array}$ & $\begin{array}{c}0.0010^{* * *} \\
(2.5293)\end{array}$ & $\begin{array}{l}0.0006 \\
(1.5983)\end{array}$ & $\begin{array}{c}0.0001 \\
(0.1209)\end{array}$ \\
\hline \multicolumn{17}{|l|}{ Firm-Level Variables } \\
\hline CAPEX / TA & $\begin{array}{c}-0.0075 \\
(-0.0518)\end{array}$ & $\begin{array}{l}-0.1258 \\
(-1.6034)\end{array}$ & $\begin{array}{l}-0.1671 * \\
(-1.7324)\end{array}$ & $\begin{array}{c}0.0489 \\
(0.3017)\end{array}$ & $\begin{array}{l}0.2840 * * \\
(2.0910)\end{array}$ & $\begin{array}{c}0.0998 \\
(1.3082)\end{array}$ & $\begin{array}{l}0.2190 * * \\
(2.3458)\end{array}$ & $\begin{array}{l}0.3318 * * \\
(2.1633)\end{array}$ & $\begin{array}{c}0.9389 * * * * \\
(6.2999)\end{array}$ & $\begin{array}{c}0.6733^{* * * *} \\
(8.1387)\end{array}$ & $\begin{array}{c}0.7723 * * * * \\
(7.4204)\end{array}$ & $\begin{array}{l}1.0015 * * * \\
(5.8842)\end{array}$ & $\begin{array}{c}1.2637 * * * \\
(6.8834)\end{array}$ & $\begin{array}{c}0.9815 * * * \\
(9.4126)\end{array}$ & $\begin{array}{l}1.3146 * * * \\
(10.2318)\end{array}$ & $\begin{array}{c}1.3372 * * * * \\
(6.3701)\end{array}$ \\
\hline ЕВIT / TA & $\begin{array}{l}-(-0.0197 *) * * \\
-0.8197 * 6\end{array}$ & $\begin{array}{l}-0.7118^{* * * *} \\
(-13.3116\end{array}$ & $\begin{array}{l}\left(-1.7203^{*} * * *\right. \\
-(-132849)\end{array}$ & $-1.0300^{* * * *}$ & $-0.6761 * * * *)$ & $\begin{array}{r}1.60060 * * * * \\
-(-11.6650)\end{array}$ & $\begin{array}{r}(.25358) \\
-0.6578^{* * * *}\end{array}$ & $\begin{array}{r}-0.8686^{*} * * * \\
(-102115)\end{array}$ & $\begin{array}{l}-0.9696 * * * * \\
-(-13.0208)\end{array}$ & $\begin{array}{l}-0.9964 * * * * \\
-(17.6768)\end{array}$ & $\begin{array}{r}1.0468 * * * \\
(-11.8913)\end{array}$ & $\begin{array}{l}-1.2653 * * * * \\
-(-134092\end{array}$ & $\begin{array}{l}(0.00304 * * \\
-0.7630 * * * \\
(-8.3184)\end{array}$ & $\begin{array}{l}-0.7723 * * * \\
(-108708)\end{array}$ & $\begin{array}{l}-0.8306 * * * * \\
-(-11.4997)\end{array}$ & $\begin{array}{l}-1.0310 * * * * \\
-8.8577\end{array}$ \\
\hline SALES $(\log )$ & $\begin{array}{c}0.0102 * * * \\
(3.4657)\end{array}$ & $\begin{array}{c}0.0072 * * * \\
(3.1938)\end{array}$ & $\begin{array}{c}0.0074^{* * * *} \\
(3.3159)\end{array}$ & $\begin{array}{c}0.0102^{* * * *} \\
(3.1753)\end{array}$ & $\begin{array}{c}0.0113004) \\
(4.0783)\end{array}$ & $\begin{array}{l}0.0115 * * 0) \\
(5.2182) \\
(-11.003)\end{array}$ & $\begin{array}{c}\left.0.0120^{* * * *}\right) \\
(5.5370)\end{array}$ & $\begin{array}{c}0.0135^{* * * *} \\
(4.4766)\end{array}$ & $\begin{array}{l}(1.028) \\
0.0428^{* * * *} \\
(14.0493)\end{array}$ & $\begin{array}{l}0.0380 * * * * 1.01 \\
(15.9431)\end{array}$ & $\begin{array}{l}0.0390^{* * * *} \\
(16.1490)\end{array}$ & $\begin{array}{l}0.0441 \text { ***** } \\
(13.1267)\end{array}$ & $\begin{array}{c}\left(1-.310441^{* * *}\right) \\
(14.4080)\end{array}$ & $\begin{array}{l}0.0540 * * * \\
(17.9697)\end{array}$ & $\begin{array}{l}0.0547 * * * * * \\
(18.3488) \\
0\end{array}$ & $\begin{array}{l}0.05677^{* * * *} \\
(13.6814)\end{array}$ \\
\hline TA Growth & $\begin{array}{c}-0.0560 * * * * \\
(-5.9417)\end{array}$ & $\begin{array}{c}-0.0046 * * \\
(-2.0195)\end{array}$ & $\begin{array}{l}-0.0041^{*} \\
(-1.7880)\end{array}$ & $\begin{array}{c}-0.0500 * * * * \\
(-5.0721)\end{array}$ & $\begin{array}{l}-0.0325 * * * * \\
(-3.6639)\end{array}$ & $\begin{array}{l}0.0041^{*} \\
(1.8453)\end{array}$ & $\begin{array}{l}0.0036^{*} \\
(1.6502)\end{array}$ & $\begin{array}{c}-0.0289 * * * * \\
(-3.0933)\end{array}$ & $\begin{array}{l}-0.0479 * * * * \\
(-4.9198)\end{array}$ & $\begin{array}{c}-0.0052 * * \\
(-2.1729)\end{array}$ & $\begin{array}{l}-0.0047 * \\
(-1.9128)\end{array}$ & $\begin{array}{c}-0.0395 * * * \\
(-3.8143)\end{array}$ & $\begin{array}{c}-0.0076 \\
(-0.6292)\end{array}$ & $\begin{array}{c}0.0035 \\
(1.1440)\end{array}$ & $\begin{array}{c}0.0036 \\
(1.1825)\end{array}$ & $\begin{array}{c}-0.0040 \\
(-0.3141)\end{array}$ \\
\hline$R \& D$ & $\begin{array}{c}-0.0482 * * * * \\
(-5.0010)\end{array}$ & & & $\begin{array}{c}0.1768 * * * \\
(3.8341)\end{array}$ & $\begin{array}{c}-0.0396 * * * \\
(-4.3577)\end{array}$ & & & $\begin{array}{l}0.0808^{*} \\
(1.8525)\end{array}$ & $\begin{array}{c}-0.0449 * * * * \\
(-4.5045)\end{array}$ & & & $\begin{array}{c}0.1469^{* * * * *} \\
(3.0338)\end{array}$ & $\begin{array}{c}-0.0313^{* * *} \\
(-2.5503)\end{array}$ & & & $\begin{array}{c}0.0587 \\
(0.9825)\end{array}$ \\
\hline SG\&A & & $\begin{array}{c}-0.0288 * * * \\
(-6.0624)\end{array}$ & & $\begin{array}{c}-0.1898^{* * * *} \\
(-5.9126)\end{array}$ & & $\begin{array}{c}-0.0180^{* * * *} \\
(-3.9060)\end{array}$ & & $\begin{array}{c}-0.1052 * * * \\
(-3.4642)\end{array}$ & & $\begin{array}{c}-0.0286^{* * * *} \\
(-5.7190)\end{array}$ & & $\begin{array}{c}-0.1617 * * * \\
(-4.7959)\end{array}$ & & $\begin{array}{c}-0.0170 * * * \\
(-2.6936)\end{array}$ & & $\begin{array}{l}-0.0693^{*} \\
(-1.6658)\end{array}$ \\
\hline Collateral Value & & & $\begin{array}{l}0.0122 * * \\
(2.4855)\end{array}$ & $\begin{array}{c}0.0140^{* * * *} \\
(2.8766)\end{array}$ & & & $\begin{array}{l}0.0087 * \\
(1.8283)\end{array}$ & $\begin{array}{l}0.0095 * * \\
(2.0593)\end{array}$ & & & $\begin{array}{c}0.0191 * * * * \\
(3.6065)\end{array}$ & $\begin{array}{l}0.0104 * * \\
(2.0298)\end{array}$ & & & $\begin{array}{c}0.0283 * * * * \\
(4.3354)\end{array}$ & $\begin{array}{l}0.0124 * \\
(1.9595)\end{array}$ \\
\hline Country-Level Variables & $-0.0508 * * * *$ & $-0.0478 * * *$ & $-0.0490 * * *$ & 0.0576 & $-0.0314 * *$ & 0.0093 & -0.0095 & 0.0405 & $-0.0478 * * * *$ & -0.0103 & $-0.0223 * *$ & -0.0168 & 0.0309 & $0.0398 * *$ & $0.0410^{* * * * *}$ & 0.0268 \\
\hline GDP per Capita (log) & $(-3.2939)$ & $(-3.8607)$ & $(-5.2143)$ & (1.4965) & $(-2.1607)$ & $(0.7770)$ & $(-1.0494)$ & (1.1108) & $(-2.9964)$ & $(-0.7895)$ & $(-2.2026)$ & $(-0.4148)$ & (1.5724) & (2.4199) & $(3.2818)$ & $(0.5371)$ \\
\hline & $0.0481 * * *$ & $0.0195^{* *}$ & $0.0242 * *$ & $0.0490^{* *}$ & 0.0257 & $0.0189 * *$ & $0.0170^{*}$ & 0.0274 & 0.0018 & $-0.0353 * * * *$ & -0.0138 & -0.0138 & $-0.0769 * * *$ & $-0.0810 * * *$ & $-0.0639 * * *$ & $-0.0914 * * * *$ \\
\hline Pvt. Credit to GDP (log) & $(2.8577)$ & & & & $(1.6181)$ & & & & & & & & & & & \\
\hline & 0.0257 & $-0.0271 * * *$ & $-0.0230 * *$ & 0.0077 & 0.0000 & $-0.0306^{* * * * *}$ & $-0.0279 * * * *$ & -0.0038 & -0.0184 & $-0.0307 * * * *$ & -0.0 & -0.0 & -0.0 & 0.01 & 0.02 & -0.0057 \\
\hline Market Cap. To GDP (log) & (1.4724) & $(-2.7606)$ & $(-2.3258)$ & $(0.3856)$ & $(0.0018)$ & $(-3.2081)$ & & $(-0.1$ & $(-1.0193)$ & $(-2.9$ & $(-1.4556)$ & $(-0.9)-9)-2$ & $(-0.2)-2)-(2)-1$ & $(1.2$ & $(1.9$ & $(-0.2216)$ \\
\hline & -0.1901 & $0.1916 * *$ & $0.1324 *$ & $-0.5639^{* * * *}$ & $-0.4049 * * *$ & $-0.4722^{* * * * *}$ & $-0.4317 * * * *$ & $-0.6999 * * *$ & 0.1823 & $0.1933^{* * *}$ & $0.1641 * *$ & 0.0459 & $-0.4307 * * * *$ & $-0.5617^{* * * *}$ & & $-0.4321 * *$ \\
\hline Law_wjp & $(-1.5191)$ & (2.3068) & (1.7168) & $(-3.3983)$ & $(-3.4324)$ & $(-5.8517)$ & $(-5.7857)$ & $(-4.4568)$ & (1.4086) & $(2.2080)$ & (1.9726) & $(0.2631)$ & $(-2.7015)$ & $(-5.0901)$ & $(-5.2941)$ & $(-2.0103)$ \\
\hline Industry Dummy & $\mathrm{Y}$ & $\mathrm{Y}$ & $\mathrm{Y}$ & $\mathrm{Y}$ & $\mathrm{Y}$ & $\mathrm{Y}$ & $\mathrm{Y}$ & $\mathrm{Y}$ & $\mathrm{Y}$ & $\mathrm{Y}$ & $\mathrm{Y}$ & $\mathrm{Y}$ & Y & $\mathrm{Y}$ & $\mathrm{Y}$ & Y \\
\hline Constant & $\begin{array}{c}0.4143 * * * \\
(3.4952)\end{array}$ & $\begin{array}{c}0.5267 * * * \\
(7.4858)\end{array}$ & $\begin{array}{c}0.4976 * * * * \\
(7.3230)\end{array}$ & $\begin{array}{c}-0.2723 \\
(-1.0980)\end{array}$ & $\begin{array}{c}0.6486 * * * * \\
(5.8051)\end{array}$ & $\begin{array}{c}0.4448 * * * * \\
(6.5058)\end{array}$ & $\begin{array}{c}0.5537 * * * * \\
(8.4193)\end{array}$ & $\begin{array}{c}0.1449 \\
(0.6173)\end{array}$ & $\begin{array}{c}0.1196 \\
(0.9752)\end{array}$ & $\begin{array}{c}0.1130 \\
(1.5227)\end{array}$ & $\begin{array}{c}0.0279 \\
(0.3802)\end{array}$ & $\begin{array}{c}-0.0511 \\
(-0.1962)\end{array}$ & $\begin{array}{c}-0.0103 \\
(-0.0682)\end{array}$ & $\begin{array}{c}-0.0149 \\
(-0.1595)\end{array}$ & $\begin{array}{c}-0.1787 * * \\
(-1.9735)\end{array}$ & $\begin{array}{c}0.0584 \\
(0.1819)\end{array}$ \\
\hline $\mathrm{Ob}$ & & & & & & & & & & 5, & & & & 5, & 4,981 & 2,1 \\
\hline R2 & & & & & & & & & 0.1 & & & & & 0.2 & 0.2243 & 0.2405 \\
\hline Adjusted R2 & 0.218 & 0.189 & 0.182 & 0.242 & 0.202 & 0.207 & 0.211 & 0.213 & 0.156 & 0.155 & 0.152 & 0.180 & 0.209 & 0.221 & 0.222 & 0.234 \\
\hline
\end{tabular}

Baseline model with firm-level robustness test variables of R\&D, SG\&A expenses, and Collateral Value of Assets.

t-statistics in parentheses, ${ }^{*} * * \mathrm{p}<0.01, * * \mathrm{p}<0.05,{ }^{*} \mathrm{p}<0.1$. 
Table 5: Firm-level robustness tests with geographical region dummy.

\begin{tabular}{|c|c|c|c|c|c|c|c|c|c|c|c|c|}
\hline & $\begin{array}{l}\text { Short-term } \\
\text { debt to market } \\
\text { value of equity }\end{array}$ & $\begin{array}{l}\text { Short-term } \\
\text { debt to market } \\
\text { value of equity }\end{array}$ & $\begin{array}{l}\text { Short-term } \\
\text { debt to market } \\
\text { value of equity }\end{array}$ & $\begin{array}{l}\text { Short-term } \\
\text { debt to book } \\
\text { value of equity }\end{array}$ & $\begin{array}{l}\text { Short-term } \\
\text { debt to book } \\
\text { value of equity }\end{array}$ & $\begin{array}{l}\text { Short-term } \\
\text { debt to book } \\
\text { value of equity }\end{array}$ & $\begin{array}{l}\text { Long-term } \\
\text { debt to market } \\
\text { value of equity }\end{array}$ & $\begin{array}{l}\text { Long-term } \\
\text { debt to market } \\
\text { value of equity }\end{array}$ & $\begin{array}{l}\text { Long-term } \\
\text { debt to market } \\
\text { value of equity }\end{array}$ & $\begin{array}{l}\text { Long-term } \\
\text { debt to book } \\
\text { value of equity }\end{array}$ & $\begin{array}{l}\text { Long-term } \\
\text { debt to book } \\
\text { value of equity }\end{array}$ & $\begin{array}{l}\text { Long-term } \\
\text { debt to book } \\
\text { value of equity }\end{array}$ \\
\hline \multicolumn{13}{|c|}{ Hofstede Cultural Dimensions } \\
\hline Individualism & $\begin{array}{c}-0.0017 * * * * \\
(-5.2846)\end{array}$ & & $\begin{array}{c}-0.0012 * * * * \\
(-2.9220)\end{array}$ & $\begin{array}{c}-0.0027 * * * \\
(-8.4169)\end{array}$ & & $\begin{array}{c}-0.0008 * * \\
(-1.9951)\end{array}$ & $\begin{array}{c}0.0009 * * \\
(2.3566)\end{array}$ & & $\begin{array}{c}0.0000 \\
(0.0270)\end{array}$ & $\begin{array}{c}0.0015^{* * * * * *} \\
(3.2949)\end{array}$ & & $\begin{array}{l}0.0010^{*} \\
(1.8002)\end{array}$ \\
\hline Masculinity & $-0.0012^{* * * * * *}$ & & $-0.0016 * * * *$ & $-0.0008 * * *$ & & $-0.0018 * * * *$ & $\begin{array}{l}-0.0007 * * \\
(-2.5201)\end{array}$ & & $\begin{array}{l}-0.0010^{* * * *} \\
(-3.4459)\end{array}$ & $\begin{array}{l}-0.0008 * * * \\
(-2.4818)\end{array}$ & & $-0.0013 * * * *$ \\
\hline Uncertainty Avoidance & $\begin{array}{c}0.0012^{* * * * *} \\
(6.3618)\end{array}$ & & $\begin{array}{c}0.0013 * * * * \\
(6.4332)\end{array}$ & $\begin{array}{c}-0.0009 * * * * \\
(-5.0928)\end{array}$ & & $\begin{array}{c}-0.0002 \\
(-1.2319)\end{array}$ & $\begin{array}{c}0.0008^{* * * * *} \\
(3.6320)\end{array}$ & & $\begin{array}{c}0.0007^{* * * *} * \\
(3.0725)\end{array}$ & $\begin{array}{c}-0.0014^{* * * *} \\
(-5.3905)\end{array}$ & & $\begin{array}{c}-0.0010^{* * * * * *} \\
(-3.4024)\end{array}$ \\
\hline Long term Orientation & $\begin{array}{c}0.0007 * * * * \\
(3.4846)\end{array}$ & & $\begin{array}{c}0.0010^{* * * * *} \\
(3.6121)\end{array}$ & $\begin{array}{c}0.0014 * * * \\
(6.6877)\end{array}$ & & $\begin{array}{c}0.0025 * * * * \\
(9.4863)\end{array}$ & $\begin{array}{l}0.0005 * * \\
(2.1925)\end{array}$ & & $\begin{array}{c}-0.0000 \\
(-0.1406)\end{array}$ & 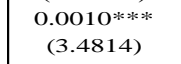 & & $\begin{array}{l}0.0007 * * \\
(2.0535)\end{array}$ \\
\hline \multicolumn{13}{|l|}{ Firm-Level Variables } \\
\hline CAPEX / TA & & $\begin{array}{l}-0.1531 * * \\
(-20797)\end{array}$ & $\begin{array}{l}-0.1665 * * \\
(-2.2859)\end{array}$ & & $0.1543 * *$ & $\begin{array}{l}0.1192 * \\
(1.6794)\end{array}$ & & $0.6502^{* * * * *}$ & $\begin{array}{l}0.6351 * * * * \\
(7.9289)\end{array}$ & & $\begin{array}{l}1.0631 * * * \\
(107364)\end{array}$ & $\begin{array}{l}1.0111^{* * * *} \\
(101871)\end{array}$ \\
\hline \multirow{2}{*}{ EBIT / TA } & & $-0.6132 * * * *$ & -0.5971 **** & & 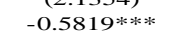 & -0.5639 **** & & $-0.8447 * * * *$ & $-0.8457 * * *$ & & $-0.6689^{* * * *}$ & $-0.6810^{* * * * * ~}$ \\
\hline & & $(-13.6699)$ & $(-13.4893)$ & & $(-13.2188)$ & $(-13.0720)$ & & $(-17.3668)$ & $(-17.3687)$ & & $(-11.0883)$ & $(-11.2871)$ \\
\hline SALES $(\log )$ & & $\begin{array}{l}0.0038^{*} \\
(1.8910)\end{array}$ & $\begin{array}{c}0.0078 * * * * \\
(3.8526)\end{array}$ & & $\begin{array}{c}0.0091 * * * \\
(4.6322)\end{array}$ & $\begin{array}{c}0.0121 * * * \\
(6.1305)\end{array}$ & & $\begin{array}{l}0.0355 * * * \\
(16.3937)\end{array}$ & $\begin{array}{c}0.0374 * * * \\
(16.7522)\end{array}$ & & $\begin{array}{c}0.0518 * * * \\
(19.3105)\end{array}$ & $\begin{array}{l}0.0530 * * * \\
(19.1548)\end{array}$ \\
\hline TA Growth & & $-0.0060^{* * * *}$ & $-0.0057 * *$ & & $0.0047 * *$ & 0.0035 & & -0.0066 **** & $-0.0061 * *$ & & 0.0037 & 0.0030 \\
\hline & & $(-2.6459)$ & $(-2.5602)$ & & (2.1080) & $(1.6251)$ & & $(-2.6825)$ & $(-2.5111)$ & & (1.2249) & (0.9979) \\
\hline \multirow{2}{*}{ GDP per Capita (log) } & & $-0.0430^{* * * *}$ & $-0.0439 * * *$ & & $-0.0402 * * * *$ & $-0.0196 *$ & & $-0.0232 * *$ & $-0.0204 *$ & & $-0.0389 * * *$ & -0.0075 \\
\hline & & $\begin{array}{l}(-4.3670) \\
0.0198 *\end{array}$ & $\begin{array}{l}(-4.1853) \\
0.0254^{* * *}\end{array}$ & & $\begin{array}{l}(-4.1639) \\
0.0576 * * *\end{array}$ & $\begin{array}{l}(-1.9120) \\
0.303 * * *\end{array}$ & & $\begin{array}{l}(-2.1793) \\
-0.0301 * * *\end{array}$ & $\begin{array}{l}(-1.7698) \\
-0.0260 * *\end{array}$ & & $(-2.9404)$ & $(-0.5276)$ \\
\hline Pvt. Credit to GDP (log) & & (1.9525) & $(2.3584)$ & & $\begin{array}{l}0.05766^{* 2 * 2 *} \\
(5.7812)\end{array}$ & $\begin{array}{c}0.0303 \times 6 \times \\
(2.8886)\end{array}$ & & 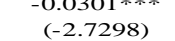 & $\begin{array}{l}-0.0260 \\
(-2.1913)\end{array}$ & & $\begin{array}{l}0.0050 \\
(0.3670)\end{array}$ & $\begin{array}{l}-0.0240 \\
(-1.6329)\end{array}$ \\
\hline Market Cap. To GDP (log) & & $-0.0393 * * * *$ & $-0.0509^{* * * *}$ & & $-0.0156^{*}$ & $-0.0376 * * *$ & & -0.0098 & $-0.0186 *$ & & $0.0342 * * *$ & 0.0066 \\
\hline Law_wjp & & $\begin{array}{c}(-4.4271) \\
0.2116 * * * \\
(2.7614)\end{array}$ & $\begin{array}{c}(-4.9996) \\
0.1730^{* * *} \\
(2.0375)\end{array}$ & & $\begin{array}{c}(-1.7925) \\
-0.2088^{* * * * *} \\
(-2.7774)\end{array}$ & $\begin{array}{c}(-3.7937) \\
-0.3415 * * * \\
(-4.1268)\end{array}$ & & $\begin{array}{l}(-1.0209) \\
0.1676^{* * *} \\
(2.0173)\end{array}$ & $\begin{array}{c}(-1.6625) \\
0.1491 \\
(1.5962)\end{array}$ & & $\begin{array}{c}(2.8643) \\
-0.0780 \\
(-0.7570)\end{array}$ & $\begin{array}{c}(0.473) \\
-0.1729 \\
(-1.4934)\end{array}$ \\
\hline Industry Dummy & Y & $\mathrm{Y}$ & Y & $\mathrm{Y}$ & $\mathrm{Y}$ & $\mathrm{Y}$ & $\mathrm{Y}$ & Y & $\mathrm{Y}$ & Y & Y & Y \\
\hline \multirow{2}{*}{ Americas } & -0.0029 & $-0.1080^{* * * *}$ & 0.0376 & $-0.0454 * *$ & -0.1096 **** & -0.0111 & -0.0389 & $-0.0605 * * * *$ & -0.0179 & $0.0582 *$ & $0.1119^{* * * *}$ & $0.0735 * *$ \\
\hline & $(-0.1257)$ & $(-5.6514)$ & (1.5588) & $(-2.0245)$ & $(-5.8470)$ & $(-0.4703)$ & $(-1.5195)$ & $(-2.9213)$ & $(-0.6761)$ & $(1.8353)$ & $(4.3531)$ & $(2.2361)$ \\
\hline \multirow[t]{2}{*}{ Asia } & $0.0809^{* * * *}$ & $0.0613 * * *$ & $0.0635^{* * * * * *}$ & -0.0188 & 0.0216 & -0.0112 & -0.0298 & $-0.0373 *$ & -0.0047 & $-0.1607^{* * * * *}$ & $-0.1582 * * *$ & $-0.1177^{* * * *}$ \\
\hline & (4.3532) & (3.1506) & (2.8349) & $(-1.0280)$ & (1.1337) & $(-0.5123)$ & $(-1.4299)$ & $(-1.7702)$ & $(-0.1905)$ & $(-6.2252)$ & $(-6.0495)$ & $(-3.8554)$ \\
\hline \multirow[t]{2}{*}{ Europe } & 0.0194 & $-0.0637 * * *$ & -0.0206 & $-0.0368 *$ & 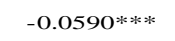 & $-0.0526 * *$ & -0.0295 & -0.0230 & -0.0091 & $-0.09866^{* * * * * *}$ & -0.0152 & -0.0459 \\
\hline & $(0.9363)$ & $(-3.0982)$ & $(-0.9437)$ & $(-1.8047)$ & $(-2.9231)$ & $(-2.4748)$ & $(-1.2671)$ & $(-1.0305)$ & $(-0.3787)$ & $(-3.4185)$ & $(-0.5513)$ & $(-1.5417)$ \\
\hline Constant & $\begin{array}{l}0.1192^{* * * * *} \\
(4.9043)\end{array}$ & $\begin{array}{c}0.5070 * * * * \\
(8.3424)\end{array}$ & 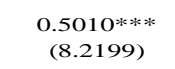 & $\begin{array}{l}0.3743^{* * * * *} \\
(15.6850)\end{array}$ & $\begin{array}{c}0.4825 * * * * \\
(8.0910)\end{array}$ & $\begin{array}{c}0.5673^{* * * * * * * ~} \\
(9.5507)\end{array}$ & $\begin{array}{c}0.1639 * * * \\
(6.0083)\end{array}$ & $\begin{array}{l}0.1431 * * \\
(2.1714)\end{array}$ & $\begin{array}{c}0.1101 \\
(1.6419)\end{array}$ & $\begin{array}{l}0.4684 \text { **:**: } \\
(13.8769)\end{array}$ & $\begin{array}{c}0.0639 \\
(0.7822)\end{array}$ & $\begin{array}{c}0.0885 \\
(1.0654)\end{array}$ \\
\hline Observations & 5,968 & 5,968 & 5,968 & 5,968 & 5,968 & 5,968 & 5,968 & 5,968 & 5,968 & 5,968 & 5,968 & 5,968 \\
\hline R2 & 0.1501 & 0.1598 & 0.1867 & 0.1589 & 0.1691 & 0.2068 & 0.0675 & 0.1389 & 0.1423 & 0.1543 & 0.2159 & 0.2204 \\
\hline Adjusted R2 & 0.149 & 0.158 & 0.184 & 0.157 & 0.167 & 0.204 & 0.0658 & 0.137 & 0.140 & 0.153 & 0.214 & 0.218 \\
\hline
\end{tabular}


The second set of firm-level robustness tests (see table 5) include dummy variables for the geographical regions of the firms. First, the results show that the signs and significance levels of our culture dimensions are stable as per main results. Second, our results provide some incremental insight on firms' capital structure choices from different geographical regions. We find that firms from Asia take on higher short-term debt-to-equity market value and lower long-term debt-to-equity book value. Important Asian countries in our sample have low IDV with high UAI and high LTO (e.g. Japan (46, 92, 88), South Korea $(18,85,100)$, Taiwan $(17,69,93)$, China $(20,30,87)$. Overall, these results goes in the direction of our baseline ones as firms from these countries take on lower debt with more short-term debt than long-term in the capital structure.

Firms from North America have lower short-term debt-to-equity market and higher long-term debt-toequity book. America's countries have high IDV with low UAI and low LTO (e.g. USA $(91,46,26)$ and Canada $(80,48,36)$. The results confirm our main findings that firms from these cultures take on higher debt and preferably more long-term debt in the capital structure.

European countries show overall lower debt-to-equity ratios, with a more significant relationship with the STD-to-equity ratios. These results confirms the perspective of some European countries sharing similar cultural values to Asian countries, hence similarly influencing their financial choices (Carr \& Tomkins, 1998). Indeed, some of the European countries have similar high levels of UAI and LTO (e.g. France $(86,63)$, Germany $(65,83)$, Belgium $(94,82)$, Italy $(75,61)$. These results in similarities in their capital structure choices.

\subsubsection{Country-level tests}

At the country-level, we perform two type of tests. First, we perform our baseline regressions but with country-level means by industry sector of firm-level financial variables (see table 6). Our results highlight that our culture dimensions signs and significance levels does not change from the baseline regressions done at the firm-level, in line with existing literature (Chui et al., 2002; Zheng et al., 2012).

Our second set of country-level tests are about legal protection of creditors and the type of a country's rule of law (see table 7). Our results show that creditors rights index (CRI) (Djankov et al., 2007) is insignificant. The measure of the legal rights index (LRI) from WBI is significant with the short-term debt-to-equity ratios but does not change cultural dimensions signs and significance. Both CRI and LRI rather have the effect of increasing the cultural coefficients values, confirming the institutional channel influence of culture. The robustness test with the origins of the rule of law of countries (Porta et al., 1998) does not change cultural dimensions signs and significance. These law variables are mostly significant with the STD-to-equity ratios, with a higher significance level with the book values. 
Table 6: Country-level robustness tests with country averages of variables by industry sector.

\begin{tabular}{|c|c|c|c|c|c|c|c|c|c|c|c|c|}
\hline Country-Level Averages & $\begin{array}{l}\text { Short-term } \\
\text { debt to market } \\
\text { value of equity }\end{array}$ & $\begin{array}{l}\text { Short-term } \\
\text { debt to market } \\
\text { value of equity }\end{array}$ & $\begin{array}{l}\text { Short-term } \\
\text { debt to market } \\
\text { value of equity }\end{array}$ & $\begin{array}{l}\text { Short-term } \\
\text { debt to book } \\
\text { value of equity }\end{array}$ & $\begin{array}{l}\text { Short-term } \\
\text { debt to book } \\
\text { value of equity }\end{array}$ & $\begin{array}{l}\text { Short-term } \\
\text { debt to book } \\
\text { value of equity }\end{array}$ & $\begin{array}{l}\text { Long-term } \\
\text { debt to market } \\
\text { value of equity }\end{array}$ & $\begin{array}{l}\text { Long-term } \\
\text { debt to market } \\
\text { value of equity }\end{array}$ & $\begin{array}{l}\text { Long-term } \\
\text { debt to market } \\
\text { value of equity }\end{array}$ & $\begin{array}{l}\text { Long-term } \\
\text { debt to book } \\
\text { value of equity }\end{array}$ & $\begin{array}{l}\text { Long-term } \\
\text { debt to book } \\
\text { value of equity }\end{array}$ & $\begin{array}{l}\text { Long-term } \\
\text { debt to book } \\
\text { value of equity }\end{array}$ \\
\hline \multicolumn{13}{|l|}{ Hofstede Cultural Dimensions } \\
\hline Individualism & $\begin{array}{c}-0.0026 * * * \\
(-50.3847)\end{array}$ & & $\begin{array}{c}-0.0012 * * * \\
(-15.0166)\end{array}$ & $\begin{array}{c}-0.0030 * * * \\
(-57.8065)\end{array}$ & & $\begin{array}{c}-0.0007 * * * \\
(-10.7725)\end{array}$ & $\begin{array}{c}0.0008 * * * \\
(18.8636)\end{array}$ & & $\begin{array}{c}0.0008 * * * \\
(10.7288)\end{array}$ & $\begin{array}{c}0.0033 * * * \\
(55.3583)\end{array}$ & & $\begin{array}{c}0.0030 * * * \\
(34.2735)\end{array}$ \\
\hline Masculinity & $\begin{array}{c}-0.0007 * * * \\
(-13.0403)\end{array}$ & & $\begin{array}{c}-0.0009 * * * \\
(-17.4989)\end{array}$ & $\begin{array}{c}-0.0007 * * * \\
(-13.0193)\end{array}$ & & $\begin{array}{c}-0.0013 * * * \\
(-30.5325)\end{array}$ & $\begin{array}{c}-0.0007 * * * * \\
(-15.3727)\end{array}$ & & $\begin{array}{c}-0.0007 * * * * \\
(-15.1867)\end{array}$ & $\begin{array}{c}-0.0013 * * * * \\
(-20.1494)\end{array}$ & & $\begin{array}{c}-0.0016 * * * \\
(-28.7939)\end{array}$ \\
\hline Uncertainty Avoidance & $\begin{array}{c}0.0011 * * * \\
(21.9354)\end{array}$ & & $\begin{array}{c}0.0015 * * * \\
(22.1685)\end{array}$ & $\begin{array}{c}-0.0009 * * * \\
(-18.4914)\end{array}$ & & $\begin{array}{c}0.0002 * * * \\
(3.9021)\end{array}$ & $\begin{array}{c}0.0008 * * * \\
(19.7866)\end{array}$ & & $\begin{array}{c}0.0005 * * * \\
(8.0758)\end{array}$ & $\begin{array}{c}-0.0016 * * * \\
(-27.4569)\end{array}$ & & $\begin{array}{c}-0.0008 * * * \\
(-11.2401)\end{array}$ \\
\hline Long term Orientation & $\begin{array}{c}0.0011 * * * \\
(19.6466)\end{array}$ & & $\begin{array}{c}0.0014 * * * \\
(18.0308)\end{array}$ & $\begin{array}{c}0.0014 * * * \\
(25.1971)\end{array}$ & & $\begin{array}{c}0.0021^{* * * * *} \\
(32.0704)\end{array}$ & $\begin{array}{c}0.0005 * * * * \\
(10.7029)\end{array}$ & & $\begin{array}{c}0.0006 * * * \\
(8.0526)\end{array}$ & $\begin{array}{l}0.0001 * \\
(1.8300)\end{array}$ & & $\begin{array}{c}0.0005 * * * \\
(5.5513)\end{array}$ \\
\hline \multicolumn{13}{|l|}{ Firm-Level Variables } \\
\hline CAPEX / TA & & $\begin{array}{c}0.1063 \\
(1.4861)\end{array}$ & $\begin{array}{c}-0.0639 \\
(-1.1979)\end{array}$ & & $\begin{array}{c}0.6858 * * * \\
(11.1799)\end{array}$ & $\begin{array}{c}0.3571 * * * \\
(7.9823)\end{array}$ & & $\begin{array}{c}-0.3675 * * * * \\
(-4.8455)\end{array}$ & $\begin{array}{c}-0.4416^{* * * * *} \\
(-9.5121)\end{array}$ & & $\begin{array}{c}-0.3675 * * * \\
(-4.8455)\end{array}$ & $\begin{array}{c}-0.5197 * * * * \\
(-9.0245)\end{array}$ \\
\hline EBIT / TA & & $\begin{array}{c}-2.2195 * * * \\
(-32.3432)\end{array}$ & $\begin{array}{c}-0.3011 * * * * \\
(-5.1837)\end{array}$ & & $\begin{array}{c}-2.3112 * * * \\
(-39.2650)\end{array}$ & $\begin{array}{c}-0.8750 * * * \\
(-17.9671)\end{array}$ & & $\begin{array}{c}2.6193 * * * \\
(35.9938)\end{array}$ & $\begin{array}{l}-0.0929 * \\
(-1.8379)\end{array}$ & & $\begin{array}{l}2.6193 * * * \\
(35.9938)\end{array}$ & $\begin{array}{c}0.8240 * * * \\
(13.1443)\end{array}$ \\
\hline SALES $(\log )$ & & $\begin{array}{c}0.0000^{* * * *} \\
(6.2381)\end{array}$ & $\begin{array}{c}0.0000^{* * * *} \\
(9.1747)\end{array}$ & & $\begin{array}{c}0.0000 * * * * \\
(7.9647)\end{array}$ & $\begin{array}{c}0.0000 * * * * \\
(6.6209)\end{array}$ & & $\begin{array}{c}-0.0000^{* * * * *} \\
(-8.8551)\end{array}$ & $\begin{array}{c}-0.0000 * * * \\
(-2.9746)\end{array}$ & & $\begin{array}{c}-0.0000 * * * * \\
(-8.8551)\end{array}$ & $\begin{array}{c}-0.0000 * * * * \\
(-7.5233)\end{array}$ \\
\hline TA Growth & & $\begin{array}{c}-0.0481 * * * \\
(-7.8110)\end{array}$ & $\begin{array}{c}-0.0212 * * * \\
(-3.7045)\end{array}$ & & $\begin{array}{c}0.1293 * * * * \\
(24.4568)\end{array}$ & $\begin{array}{c}0.0922 * * * \\
(19.2175)\end{array}$ & & $\begin{array}{c}0.2179 * * * \\
(33.3297)\end{array}$ & $\begin{array}{c}-0.0221 * * * \\
(-4.4350)\end{array}$ & & $\begin{array}{c}0.2179 * * * \\
(33.3297)\end{array}$ & $\begin{array}{l}0.1722 * * * \\
(27.8663)\end{array}$ \\
\hline \multicolumn{13}{|l|}{ Country-Level Variables } \\
\hline GDP per Capita (log) & & $\begin{array}{c}-0.1090 * * * \\
(-41.2638)\end{array}$ & $\begin{array}{c}-0.0492 * * * \\
(-20.6679)\end{array}$ & & $\begin{array}{c}-0.0937 * * * \\
(-41.3432)\end{array}$ & $\begin{array}{c}-0.0259 * * * \\
(-13.0023)\end{array}$ & & $\begin{array}{c}0.0839 * * * \\
(29.9689)\end{array}$ & $\begin{array}{c}-0.0158 * * * \\
(-7.6171)\end{array}$ & & $\begin{array}{c}0.0839 * * * \\
(29.9689)\end{array}$ & $\begin{array}{c}0.0372 * * * \\
(14.4640)\end{array}$ \\
\hline Pvt. Credit to GDP (log) & & $\begin{array}{l}-0.0302 * * * \\
(-10.5349)\end{array}$ & $\begin{array}{c}-0.0133 * * * * \\
(-5.4888)\end{array}$ & & $\begin{array}{c}-0.0218 * * * * \\
(-8.8514)\end{array}$ & $\begin{array}{c}-0.0220 * * * \\
(-10.8138)\end{array}$ & & $\begin{array}{c}0.0317 * * * \\
(10.4303)\end{array}$ & $\begin{array}{c}-0.0134 * * * * \\
(-6.3712)\end{array}$ & & $\begin{array}{c}0.0317 * * * \\
(10.4303)\end{array}$ & $\begin{array}{c}0.0136 * * * \\
(5.2101)\end{array}$ \\
\hline Market Cap. To GDP (log) & & $\begin{array}{c}0.0573 * * * \\
(19.7752)\end{array}$ & $\begin{array}{c}0.0196 * * * \\
(8.1976)\end{array}$ & & $\begin{array}{c}0.0635 * * * \\
(25.5377)\end{array}$ & $\begin{array}{c}0.0152 * * * \\
(7.5802)\end{array}$ & & $\begin{array}{c}-0.0790 * * * \\
(-25.7141)\end{array}$ & $\begin{array}{c}-0.0173 * * * \\
(-8.2974)\end{array}$ & & $\begin{array}{c}-0.0790 * * * \\
(-25.7141)\end{array}$ & $\begin{array}{c}-0.0542 * * * \\
(-20.9962)\end{array}$ \\
\hline Law_wjp & & $\begin{array}{c}0.4237 * * * \\
(17.4430)\end{array}$ & $\begin{array}{c}0.0826 * * * \\
(3.4814)\end{array}$ & & $\begin{array}{c}0.2004 * * * \\
(9.6189)\end{array}$ & $\begin{array}{c}-0.2357 * * * \\
(-11.8414)\end{array}$ & & $\begin{array}{c}-0.1598 * * * \\
(-6.2036)\end{array}$ & $\begin{array}{c}0.1297 * * * \\
(6.2818)\end{array}$ & & $\begin{array}{c}-0.1598 * * * \\
(-6.2036)\end{array}$ & $\begin{array}{c}-0.1411 * * * \\
(-5.5050)\end{array}$ \\
\hline Industry Dummy & $\mathrm{Y}$ & $\mathrm{Y}$ & $\mathrm{Y}$ & $\mathrm{Y}$ & $\mathrm{Y}$ & $\mathrm{Y}$ & $\mathrm{Y}$ & $\mathrm{Y}$ & $\mathrm{Y}$ & $\mathrm{Y}$ & $\mathrm{Y}$ & $\mathrm{Y}$ \\
\hline Constant & $\begin{array}{c}0.1758 * * * \\
(30.9697)\end{array}$ & $\begin{array}{l}1.0265 * * * \\
(41.4378)\end{array}$ & $\begin{array}{c}0.5367 * * * \\
(25.2391)\end{array}$ & $\begin{array}{l}0.3565^{* * * *} \\
(62.3134)\end{array}$ & $\begin{array}{c}0.7712 * * * \\
(36.2929)\end{array}$ & $\begin{array}{c}0.5517 * * * \\
(30.9421)\end{array}$ & $\begin{array}{c}0.1362 * * * \\
(29.1915)\end{array}$ & $\begin{array}{c}-0.6009 \text { **** } \\
(-22.8756)\end{array}$ & $\begin{array}{c}0.4146 * * * \\
(22.4092)\end{array}$ & $\begin{array}{c}0.3643 * * * \\
(54.0422)\end{array}$ & $\begin{array}{c}-0.6009 * * * \\
(-22.8756)\end{array}$ & $\begin{array}{c}-0.0226 \\
(-0.9844)\end{array}$ \\
\hline Observations & 5,436 & 5,436 & 5,436 & 5,436 & 5,436 & 5,436 & 5,436 & 5,436 & 5,436 & 5,436 & 5,436 & 5,436 \\
\hline R2 & 0.7091 & 0.5464 & 0.7563 & 0.7130 & 0.6758 & 0.8336 & 0.6377 & 0.7195 & 0.6599 & 0.7744 & 0.7195 & 0.8439 \\
\hline Adjusted R2 & 0.709 & 0.545 & 0.756 & 0.713 & 0.675 & 0.833 & 0.637 & 0.719 & 0.659 & 0.774 & 0.719 & 0.843 \\
\hline
\end{tabular}


Table 7: Country-level robustness tests with investor protection and rule of law origins.

\begin{tabular}{|c|c|c|c|c|c|c|c|c|c|c|c|c|}
\hline & $\begin{array}{l}\text { Short-term } \\
\text { debt to market } \\
\text { value of equity }\end{array}$ & $\begin{array}{l}\text { Short-term } \\
\text { debt to market } \\
\text { value of equity }\end{array}$ & $\begin{array}{l}\text { Short-term } \\
\text { debt to market } \\
\text { value of equity }\end{array}$ & $\begin{array}{l}\text { Short-term } \\
\text { debt to book } \\
\text { value of equity }\end{array}$ & $\begin{array}{l}\text { Short-term } \\
\text { debt to book } \\
\text { value of equity }\end{array}$ & $\begin{array}{l}\text { Short-term } \\
\text { debt to book } \\
\text { value of equity }\end{array}$ & \begin{tabular}{|l} 
Long-term \\
debt to market \\
value of equity
\end{tabular} & $\begin{array}{l}\text { Long-term } \\
\text { debt to market } \\
\text { value of equity }\end{array}$ & $\begin{array}{l}\text { Long-term } \\
\text { debt to market } \\
\text { value of equity }\end{array}$ & $\begin{array}{l}\text { Long-term } \\
\text { debt to book } \\
\text { value of equity }\end{array}$ & $\begin{array}{l}\text { Long-term } \\
\text { debt to book } \\
\text { value of equity }\end{array}$ & $\begin{array}{l}\text { Long-term } \\
\text { debt to book } \\
\text { value of equity }\end{array}$ \\
\hline \multicolumn{13}{|c|}{ Hofstede Cultural Dimensions } \\
\hline Individualism & $\begin{array}{c}-0.0019^{* * * * *} \\
(-6.4658)\end{array}$ & $\begin{array}{c}-0.0026 * * * * \\
(-8.1862)\end{array}$ & $\begin{array}{c}-0.0024 * * * \\
(-7.3148)\end{array}$ & $\begin{array}{c}-0.0013 * * * * \\
(-4.4230)\end{array}$ & $\begin{array}{c}-0.0012^{* * * *} \\
(-3.7862)\end{array}$ & $\begin{array}{c}-0.0007^{* * *} \\
(-2.1392)\end{array}$ & $\begin{array}{c}-0.0001 \\
(-0.2979)\end{array}$ & $\begin{array}{c}-0.0003 \\
(-0.7187)\end{array}$ & $\begin{array}{c}-0.0011^{* * * *} \\
(-3.1467)\end{array}$ & $\begin{array}{c}0.0027 * * * * \\
(6.6162)\end{array}$ & $\begin{array}{c}0.0024 * * * \\
(5.3928)\end{array}$ & $\begin{array}{c}0.0021 * * * * \\
(4.6256)\end{array}$ \\
\hline Masculinity & $\begin{array}{c}-0.0008 * * * \\
(-4.0324)\end{array}$ & $\begin{array}{c}-0.0007 * * * \\
(-3.6837)\end{array}$ & $\begin{array}{c}-0.0006 * * \\
(-2.4393)\end{array}$ & $\begin{array}{c}-0.0014 * * * \\
(-7.3810)\end{array}$ & $\begin{array}{c}-0.0012 * * * \\
(-6.2384)\end{array}$ & $\begin{array}{c}-0.0019 * * * \\
(-7.7053)\end{array}$ & $\begin{array}{c}-0.0009 * * * \\
(-4.4054)\end{array}$ & $\begin{array}{c}-0.0010 * * * \\
(-4.7229)\end{array}$ & $\begin{array}{c}-0.0000 \\
(-0.1767)\end{array}$ & $\begin{array}{c}-0.0021 * * * \\
(-7.8583)\end{array}$ & $\begin{array}{c}-0.0021 * * * \\
(-7.6099)\end{array}$ & $\begin{array}{c}-0.0025 * * * \\
(-7.1573)\end{array}$ \\
\hline Uncertainty Avoidance & $\begin{array}{c}0.0012^{* * * * *} \\
(5.6622)\end{array}$ & $\begin{array}{c}0.0017 * * * \\
(7.9652)\end{array}$ & $\begin{array}{c}0.0011 * * * * \\
(5.0164)\end{array}$ & $\begin{array}{c}-0.0003 \\
(-1.5080)\end{array}$ & $\begin{array}{l}-0.0000 \\
(-0.1022)\end{array}$ & $\begin{array}{l}-0.0001 \\
(-0.6765)\end{array}$ & $\begin{array}{c}0.0008 * * * \\
(3.3616)\end{array}$ & $\begin{array}{c}0.0007 * * * * \\
(2.7389)\end{array}$ & $\begin{array}{c}0.0007 * * * \\
(3.0586)\end{array}$ & $\begin{array}{c}-0.0011 * * * * \\
(-3.8167)\end{array}$ & $\begin{array}{c}-0.0011 * * * \\
(-3.7137)\end{array}$ & $\begin{array}{c}-0.0012 * * * \\
(-3.8319)\end{array}$ \\
\hline Long term Orientation & $\begin{array}{c}0.0010 * * * * \\
(3.9514)\end{array}$ & $\begin{array}{c}0.0010 * * * \\
(3.7595)\end{array}$ & $\begin{array}{c}0.0025 * * * * \\
(6.0795)\end{array}$ & $\begin{array}{c}0.0023 * * * * \\
(9.3559)\end{array}$ & $\begin{array}{c}0.0020 * * * \\
(8.0459)\end{array}$ & $\begin{array}{c}0.0026 * * * \\
(6.5243)\end{array}$ & $\begin{array}{c}-0.0001 \\
(-0.2625)\end{array}$ & $\begin{array}{c}0.0001 \\
(0.2046)\end{array}$ & $\begin{array}{c}0.0016 \text { **** } \\
(3.4329)\end{array}$ & $\begin{array}{l}0.0007 * * * \\
(2.0786)\end{array}$ & $\begin{array}{c}0.0007 * * \\
(2.0309)\end{array}$ & $\begin{array}{c}-0.0003 \\
(-0.5903)\end{array}$ \\
\hline Firm-Level Variables & $\mathrm{Y}$ & $\mathrm{Y}$ & $\mathrm{Y}$ & $\mathrm{Y}$ & $\mathrm{Y}$ & $\mathrm{Y}$ & $\mathrm{Y}$ & $\mathrm{Y}$ & $\mathrm{Y}$ & $\mathrm{Y}$ & $\mathrm{Y}$ & $\mathrm{Y}$ \\
\hline Country-Level Variables & $\mathrm{Y}$ & $\mathrm{Y}$ & $\mathrm{Y}$ & $\mathrm{Y}$ & $\mathrm{Y}$ & $\mathrm{Y}$ & $\mathrm{Y}$ & $\mathrm{Y}$ & $\mathrm{Y}$ & $\mathrm{Y}$ & $\mathrm{Y}$ & $\mathrm{Y}$ \\
\hline Law_wjp & $\begin{array}{l}0.1374 * \\
(1.8957)\end{array}$ & $\begin{array}{c}0.1163 \\
(1.5952)\end{array}$ & $\begin{array}{c}0.2106 * * \\
(2.4997)\end{array}$ & $\begin{array}{c}-0.4096 * * * * \\
(-5.8134)\end{array}$ & $\begin{array}{c}-0.5041 * * * * \\
(-7.1040)\end{array}$ & $\begin{array}{c}-0.4485 * * * \\
(-5.4400)\end{array}$ & $\begin{array}{c}0.1613 * * \\
(2.0311)\end{array}$ & $\begin{array}{c}0.2048 * * \\
(2.5075)\end{array}$ & $\begin{array}{c}0.2437 * * * \\
(2.6348)\end{array}$ & $\begin{array}{c}-0.5367 * * * \\
(-5.4391)\end{array}$ & $\begin{array}{c}-0.4983 * * * \\
(-4.8711)\end{array}$ & $\begin{array}{c}-0.2873 * * \\
(-2.4827)\end{array}$ \\
\hline CRI & $\begin{array}{c}-0.0062 \\
(-1.2712)\end{array}$ & & & $\begin{array}{c}-0.0053 \\
(-1.1164)\end{array}$ & & & $\begin{array}{c}0.0023 \\
(0.4376)\end{array}$ & & & $\begin{array}{c}0.0099 \\
(1.4815)\end{array}$ & & \\
\hline LRI & & $\begin{array}{c}0.0150 * * * \\
(6.2536)\end{array}$ & & & $\begin{array}{l}0.0047^{* * *} \\
(2.0205)\end{array}$ & & & $\begin{array}{c}-0.0009 \\
(-0.3351)\end{array}$ & & & $\begin{array}{c}0.0010 \\
(0.3030)\end{array}$ & \\
\hline Law_ENG & & & 0.0036 & & & $-0.0843 * * *$ & & & 0.0525 & & & 0.0605 \\
\hline & & & $(0.1126)$ & & & $(-2.6934)$ & & & (1.4958) & & & $(1.3755)$ \\
\hline Law_FRA & & & -0.0489 & & & $-0.1243^{* * * *}$ & & & 0.0311 & & & 0.0534 \\
\hline & & & $(-1.5317)$ & & & $(-3.9753)$ & & & $(0.8859)$ & & & $(1.2158)$ \\
\hline Law_DEU & & & $-0.1261 * * *$ & & & $-0.0771 * *$ & & & $-0.1122^{* * * *}$ & & & 0.0829 \\
\hline & & & $(-3.3900)$ & & & $(-2.1195)$ & & & $(-2.7475)$ & & & (1.6235) \\
\hline Law_SCAN & & & $-0.0727 * *$ & & & $-0.1060^{* * * *}$ & & & 0.0305 & & & -0.0408 \\
\hline & & & $(-1.9824)$ & & & $(-2.9512)$ & & & $(0.7566)$ & & & $(-0.8091)$ \\
\hline Industry Dummy & $\mathrm{Y}$ & $\mathrm{Y}$ & $\mathrm{Y}$ & $\mathrm{Y}$ & $\mathrm{Y}$ & $\mathrm{Y}$ & $\mathrm{Y}$ & $\mathrm{Y}$ & $\mathrm{Y}$ & $\mathrm{Y}$ & $\mathrm{Y}$ & $\mathrm{Y}$ \\
\hline Constant & $\begin{array}{c}0.5029 * * * \\
(9.0640)\end{array}$ & $\begin{array}{c}0.4451^{* * * *} \\
(7.9735)\end{array}$ & $\begin{array}{c}0.4145 * * * * \\
(5.7570)\end{array}$ & $\begin{array}{c}0.5227 * * * * \\
(9.6890)\end{array}$ & $\begin{array}{c}0.4655^{* * * *} \\
(8.5657)\end{array}$ & $\begin{array}{c}0.6714 * * * \\
(9.5283)\end{array}$ & $\begin{array}{l}0.1138^{*} \\
(1.8710)\end{array}$ & $\begin{array}{l}0.1369 * * \\
(2.1895)\end{array}$ & $\begin{array}{c}-0.1022 \\
(-1.2924)\end{array}$ & $\begin{array}{c}-0.0865 \\
(-1.1455)\end{array}$ & $\begin{array}{c}-0.0884 \\
(-1.1289)\end{array}$ & $\begin{array}{c}0.0126 \\
(0.1274)\end{array}$ \\
\hline Observations & 5,954 & 5,578 & 5,840 & 5,954 & 5,578 & 5,840 & 5,954 & 5,578 & 5,840 & 5,954 & 5,578 & 5,840 \\
\hline & 0.1822 & 0.1867 & 0.1895 & 0.2056 & 0.2104 & 0.2107 & 0.1420 & 0.1429 & 0.1526 & 0.2155 & 0.2157 & 0.2186 \\
\hline Adjusted R2 & 0.180 & 0.184 & 0.187 & 0.203 & 0.208 & 0.208 & 0.140 & 0.140 & 0.150 & 0.213 & 0.213 & 0.216 \\
\hline
\end{tabular}




\subsubsection{Sample-level tests}

We perform two sample-level testes. The first test splits our sample in four quantiles by firm size (see table 8), as firms' size is said to play a role in their capital structure (Rajan \& Zingales, 1995; Ferris et al., 2018). Second, we remove firms from USA and Japan as these for the baseline model (see table 9).

We present our first sample-level test results (see table 8). We find that IDV has a negative relationship with the STD to equity ratios, which is significant mostly for quantiles Q3 and Q4. It suggests that large firms from collectivist cultures (low IDV) have a higher STD to in the capital structures. IDV negative relationship extends to Q1 but only for the equity market ratio. This result meets Ferris et al. (2018) as they find that small firms have a higher market-to-book ratio, hence they prefer using the equity market value for raising debt in the capital structure.

IDV has a significant positive relationship with LTD to book value of equity in all quartiles of firms' size. It confirms our hypothesis $\mathrm{H} 2 \mathrm{a}$ and highlights that firms from individualist cultures use their equity book value rather than market value in their capital structure choices. The result contributes a new cultural perspective to Ferris et al. (2018) findings on firms aligning their debt in the capital structure to the higher of equity market or book value. Our results highlight that all firms from high IDV culture prefer to use equity book value in their capital structure.

MAS has a significant negative association with STD to equity ratios in Q1 to Q3, and insignificant for Q4. This suggest that firms from higher feminine cultures (low MAS) take on more debt whether it is against equity market or book value. MAS relationship sign between Q1 and Q3 confirms existing literature (Chang et al., 2012; Zheng et al., 2012), while contributing a new result for the largest firms that of culture irrelevance.

MAS has a significant negative association with firms LTD to equity ratios meeting existing literature on culture and debt maturity (Chang et al., 2012; Zheng et al., 2012). Firms from feminine cultures take on more debt in their capital structure than diluting their equity.

UAI has a significant positive association with short-term debt to market value of equity in Q1 to Q3 and negative association with short-term debt to book value of equity in Q3 and Q4. These results first suggests that smaller firms from high UAI cultures tend to take on higher debt based on the equity market than book value. Second, larger firms from low UAI cultures prefer to take on higher debt from equity book than market value. His is in line with our hypothesis H2c that low UAI firm would tend to take on more debt in their capital structure, which seems to be true even for their short-term debt. These findings contribute new knowledge to culture and debt literature (Chang et al., 2012; Zheng et al., 2012). 
Table 8: Sample-level robustness test with sample split in quartiles by firm size.

\begin{tabular}{|c|c|c|c|c|c|c|c|c|c|c|c|c|c|c|c|c|}
\hline & \multicolumn{2}{|c|}{ Q1 } & \multicolumn{2}{|c|}{ Q2 } & \multicolumn{2}{|c|}{ Q3 } & \multicolumn{2}{|r|}{ Q4 } & \multicolumn{2}{|r|}{ Q1 } & \multicolumn{2}{|c|}{ Q2 } & \multicolumn{2}{|c|}{ Q3 } & \multicolumn{2}{|c|}{ Q4 } \\
\hline & $\begin{array}{l}\text { Short-term } \\
\text { debt to market } \\
\text { value of equity }\end{array}$ & $\begin{array}{l}\text { Short-term } \\
\text { debt to book } \\
\text { value of equity }\end{array}$ & \begin{tabular}{|l} 
Short-term \\
debt to market \\
value of equity
\end{tabular} & $\begin{array}{l}\text { Short-term } \\
\text { t debt to book } \\
\text { value of equity }\end{array}$ & $\begin{array}{l}\text { Short-term } \\
\text { debt to market } \\
\text { value of equity }\end{array}$ & $\begin{array}{l}\text { Short-term } \\
t \text { debt to book } \\
\text { value of equity }\end{array}$ & \begin{tabular}{|l} 
Short-term \\
debt to market \\
value of equity
\end{tabular} & $\begin{array}{l}\text { Short-term } \\
\text { t debt to book } \\
\text { y value of equity }\end{array}$ & $\begin{array}{l}\text { Long-term } \\
\text { debt to market } \\
\text { value of equity }\end{array}$ & $\begin{array}{l}\text { Long-term } \\
\text { et debt to book } \\
\text { y value of equity }\end{array}$ & $\begin{array}{l}\text { Long-term } \\
\text { debt to market } \\
\text { value of equity }\end{array}$ & $\begin{array}{l}\text { Long-term } \\
\text { t debt to book } \\
\text { value of equity }\end{array}$ & $\begin{array}{l}\text { Long-term } \\
\text { debt to market } \\
\text { value of equity }\end{array}$ & $\begin{array}{l}\text { Long-term } \\
t \text { debt to book } \\
\text { value of equity }\end{array}$ & $\begin{array}{l}\text { Long-term } \\
\text { debt to market } \\
\text { value of equity }\end{array}$ & $\begin{array}{l}\text { Long-term } \\
\text { debt to book } \\
\text { value of equity }\end{array}$ \\
\hline \multicolumn{17}{|c|}{ Hofstede Cultural Dimensions } \\
\hline Individualism & $\begin{array}{c}-0.0024 * * * \\
(-4.0495)\end{array}$ & $\begin{array}{c}-0.0009 \\
(-1.5025)\end{array}$ & $\begin{array}{c}-0.0007 \\
(-1.0817)\end{array}$ & $\begin{array}{c}-0.0009 \\
(-1.5311)\end{array}$ & $\begin{array}{c}-0.0012^{* * *} \\
(-2.1403)\end{array}$ & $\begin{array}{c}-0.0016^{* * * *} \\
(-3.0242)\end{array}$ & $\begin{array}{c}-0.0022^{* * *} \\
(-4.4317)\end{array}$ & $\begin{array}{c}-0.0019^{* * *} \\
(-3.5403)\end{array}$ & $\begin{array}{c}-0.0007 \\
(-1.2659)\end{array}$ & $\begin{array}{c}0.0017^{* * *} \\
(2.4354)\end{array}$ & $\begin{array}{c}0.0006 \\
(1.0921)\end{array}$ & $\begin{array}{c}0.0019^{* * * *} \\
(2.7618)\end{array}$ & $\begin{array}{c}0.0009 \\
(1.2992)\end{array}$ & $\begin{array}{c}0.0022 * * * \\
(2.6542)\end{array}$ & $\begin{array}{c}0.0006 \\
(0.8881)\end{array}$ & $\begin{array}{c}0.0039 * * * \\
(3.9103)\end{array}$ \\
\hline Masculinity & $\begin{array}{c}-0.0016^{* * * *} \\
(-3.4237)\end{array}$ & $\begin{array}{c}-0.0019^{* * * *} \\
(-4.0876)\end{array}$ & $\begin{array}{c}-0.0023^{* * * *} \\
(-5.4288)\end{array}$ & $\begin{array}{c}-0.0023^{* * * *} \\
(-5.4712)\end{array}$ & $\begin{array}{l}-0.0007^{*} \\
(-1.8330)\end{array}$ & $\begin{array}{c}-0.0009^{* *} \\
(-2.5778)\end{array}$ & $\begin{array}{c}0.0002 \\
(0.5636)\end{array}$ & $\begin{array}{c}-0.0002 \\
(-0.6864)\end{array}$ & $\begin{array}{c}-0.0012^{* * * *} \\
(-2.5820)\end{array}$ & $\begin{array}{c}-0.0017^{* * *} \\
(-3.0819)\end{array}$ & $\begin{array}{c}-0.0014^{* * * *} \\
(-3.4344)\end{array}$ & $\begin{array}{c}-0.0017^{* * * *} \\
(-3.4477)\end{array}$ & $\begin{array}{c}-0.0015^{* * * *} \\
(-3.2651)\end{array}$ & $\begin{array}{c}-0.0021^{* * * *} \\
(-3.9434)\end{array}$ & $\begin{array}{c}-0.0011^{* *} \\
(-2.4801)\end{array}$ & $\begin{array}{c}-0.0019^{* * * *} \\
(-3.1341)\end{array}$ \\
\hline Uncertainty Avoidance & $\begin{array}{c}0.0010^{* * *} \\
(2.5690)\end{array}$ & $\begin{array}{l}0.0009 * * \\
(2.3735)\end{array}$ & $\begin{array}{c}0.0025 * * * * \\
(5.6829)\end{array}$ & $\begin{array}{c}0.0003 \\
(0.6551)\end{array}$ & $\begin{array}{l}0.0008^{*} \\
(1.7669)\end{array}$ & $\begin{array}{c}-0.0013^{* * * *} \\
(-3.2960)\end{array}$ & $\begin{array}{c}-0.0001 \\
(-0.3648)\end{array}$ & $\begin{array}{c}-0.0015^{* * * *} \\
(-3.8626)\end{array}$ & $\begin{array}{c}-0.0001 \\
(-0.4061)\end{array}$ & $\begin{array}{c}-0.0010 * * \\
(-2.3702)\end{array}$ & $\begin{array}{c}0.0004 \\
(1.0928)\end{array}$ & $\begin{array}{c}-0.0013^{* * * *} \\
(-2.6166)\end{array}$ & $\begin{array}{c}0.0012^{* *} \\
(2.3294)\end{array}$ & $\begin{array}{c}-0.0003 \\
(-0.5188)\end{array}$ & $\begin{array}{l}0.0013^{* * *} \\
(2.4801)\end{array}$ & $\begin{array}{l}-0.0012^{*} \\
(-1.6545)\end{array}$ \\
\hline Long term Orientation & $\begin{array}{c}-0.0001 \\
(-0.1484)\end{array}$ & $\begin{array}{c}0.0019 * * * \\
(3.8727)\end{array}$ & $\begin{array}{c}0.0015 * * * \\
(2.6317)\end{array}$ & $\begin{array}{c}0.0023 * * * \\
(4.2547)\end{array}$ & $\begin{array}{c}0.0023 * * * * \\
(4.2001)\end{array}$ & $\begin{array}{c}0.0024 * * * \\
(4.8539)\end{array}$ & $\begin{array}{c}0.0014 * * * \\
(3.0155)\end{array}$ & $\begin{array}{c}0.0021 * * * \\
(4.1109)\end{array}$ & $\begin{array}{c}-0.0002 \\
(-0.3427)\end{array}$ & $\begin{array}{c}0.0015 \text { *** } \\
(2.5399)\end{array}$ & $\begin{array}{c}-0.0000 \\
(-0.0552)\end{array}$ & $\begin{array}{c}0.0002 \\
(0.3715)\end{array}$ & $\begin{array}{l}-0.0002 \\
(-0.3031)\end{array}$ & $\begin{array}{c}-0.0012 \\
(-1.5452)\end{array}$ & $\begin{array}{c}0.0007 \\
(1.0234)\end{array}$ & $\begin{array}{c}0.0014 \\
(1.4618)\end{array}$ \\
\hline Firm-Level Variables & & & & & & & & & & & & & & & & \\
\hline CAPEX / TA & $\begin{array}{c}-0.1409 \\
(-1.2845)\end{array}$ & $\begin{array}{c}0.0629 \\
(0.5816)\end{array}$ & $\begin{array}{c}-0.0662 \\
(-0.3847)\end{array}$ & $\begin{array}{l}0.3591^{* * *} \\
(2.1622)\end{array}$ & $\begin{array}{c}-0.0657 \\
(-0.3914)\end{array}$ & $\begin{array}{l}0.3827 * * \\
(2.4511)\end{array}$ & $\begin{array}{c}-0.1836 \\
(-1.1314)\end{array}$ & $\begin{array}{l}-0.2932^{*} \\
(-1.6682)\end{array}$ & $\begin{array}{c}0.3508^{* * * *} \\
(3.3622)\end{array}$ & $\begin{array}{c}0.6704 * * * \\
(5.3452)\end{array}$ & $\begin{array}{c}1.0113 * * * * \\
(6.2923)\end{array}$ & $\begin{array}{c}1.4758^{* * * *} \\
(7.6705)\end{array}$ & $\begin{array}{c}0.9172^{* * * * *} \\
(4.5358)\end{array}$ & $\begin{array}{c}1.7610^{* * * *} \\
(7.3084)\end{array}$ & $\begin{array}{c}0.9258^{* * * *} \\
(3.9994)\end{array}$ & $\begin{array}{c}0.9237^{* * * *} \\
(2.8163)\end{array}$ \\
\hline EBIT / TA & $\begin{array}{c}-0.3122^{* * * *} \\
(-4.2993)\end{array}$ & $\begin{array}{c}-0.3671^{* * * *} \\
(-5.1301)\end{array}$ & $\begin{array}{c}-1.1283^{* * * *} \\
(-9.3180)\end{array}$ & $\begin{array}{c}-0.9332^{* * * * *} \\
(-7.9808)\end{array}$ & $\begin{array}{c}-0.8577^{* * * *} \\
(-9.4179)\end{array}$ & $\begin{array}{c}-0.6859^{* * * *} \\
(-8.1015)\end{array}$ & $\begin{array}{c}-1.2180^{* * * *} \\
(-11.8671)\end{array}$ & $\begin{array}{c}-1.0203^{* * *} \\
(-9.1780)\end{array}$ & $\begin{array}{c}-0.3128^{* * * *} \\
(-4.5287)\end{array}$ & $\begin{array}{c}-0.4189^{* * * *} \\
(-5.0455)\end{array}$ & $\begin{array}{c}-1.2268^{* * * *} \\
(-10.8401)\end{array}$ & $\begin{array}{c}-1.0653^{* * * *} \\
(-7.8633)\end{array}$ & $\begin{array}{c}-1.1009^{* * *} \\
(-10.0412)\end{array}$ & $\begin{array}{c}-0.6764^{* * * *} \\
(-5.1767)\end{array}$ & $\begin{array}{c}-2.2493^{* * * *} \\
(-15.3597)\end{array}$ & $\begin{array}{c}-1.4950^{* * * *} \\
(-7.2047)\end{array}$ \\
\hline SALES (log) & $\begin{array}{c}0.0444 * * * \\
(5.2709)\end{array}$ & $\begin{array}{c}0.0354 * * * \\
(4.2583)\end{array}$ & $\begin{array}{l}0.0483^{* * *} \\
(2.2655)\end{array}$ & $\begin{array}{l}0.0476^{* * *} \\
(2.3151)\end{array}$ & $\begin{array}{c}0.0096 \\
(0.5561)\end{array}$ & $\begin{array}{c}0.0111 \\
(0.6883)\end{array}$ & $\begin{array}{l}0.0116 * * \\
(2.2074)\end{array}$ & $\begin{array}{c}0.0168 * * * \\
(2.9439)\end{array}$ & $\begin{array}{c}0.0449^{* * * *} \\
(5.5959)\end{array}$ & $\begin{array}{c}0.0332 * * * \\
(3.4418)\end{array}$ & $\begin{array}{c}0.0622 * * * \\
(3.1268)\end{array}$ & $\begin{array}{c}0.0748^{* * * *} \\
(3.1396)\end{array}$ & $\begin{array}{c}0.0280 \\
(1.3413)\end{array}$ & $\begin{array}{l}0.0420 * \\
(1.6883)\end{array}$ & $\begin{array}{c}0.0293 * * * \\
(3.9085)\end{array}$ & $\begin{array}{c}0.0327 * * * \\
(3.0737)\end{array}$ \\
\hline TA Growth & $\begin{array}{c}-0.0011 \\
(-0.4426)\end{array}$ & $\begin{array}{l}0.0060^{* * *} \\
(2.4511)\end{array}$ & $\begin{array}{c}-0.0207 * * \\
(-2.3349)\end{array}$ & $\begin{array}{c}0.0031 \\
(0.3585)\end{array}$ & $\begin{array}{c}-0.0463^{* * * *} \\
(-2.5907)\end{array}$ & $\begin{array}{c}0.0134 \\
(0.8084)\end{array}$ & $\begin{array}{c}-0.0265^{* * * *} \\
(-2.6429)\end{array}$ & $\begin{array}{l}-0.0197 * \\
(-1.8140)\end{array}$ & $\begin{array}{c}-0.0017 \\
(-0.7010)\end{array}$ & $\begin{array}{c}0.0045 \\
(1.5805)\end{array}$ & $\begin{array}{c}-0.0222^{* * * *} \\
(-2.6888)\end{array}$ & $\begin{array}{c}-0.0058 \\
(-0.5895)\end{array}$ & $\begin{array}{c}-0.0828 * * * * \\
(-3.8488)\end{array}$ & $\begin{array}{c}0.0348 \\
(1.3577)\end{array}$ & $\begin{array}{c}-0.0375^{* * * *} \\
(-2.6238)\end{array}$ & $\begin{array}{c}-0.0112 \\
(-0.5523)\end{array}$ \\
\hline Country-Level Variables & & & & & & & & & & & & & & & & \\
\hline GDP per Capita (log) & $\begin{array}{c}-0.0877^{* * * * *} \\
(-5.1183)\end{array}$ & $\begin{array}{c}-0.0555 * * * * \\
(-3.2869)\end{array}$ & $\begin{array}{c}-0.0474 * * * * \\
(-2.8053)\end{array}$ & $\begin{array}{c}-0.0045 \\
(-0.2756)\end{array}$ & $\begin{array}{l}-0.0214 \\
(-1.3423)\end{array}$ & $\begin{array}{c}-0.0061 \\
(-0.4134)\end{array}$ & $\begin{array}{c}0.0111 \\
(0.6837)\end{array}$ & $\begin{array}{c}0.0084 \\
(0.4783)\end{array}$ & $\begin{array}{l}-0.0170 \\
(-1.0437)\end{array}$ & $\begin{array}{c}0.0316 \\
(1.6153)\end{array}$ & $\begin{array}{c}-0.0038 \\
(-0.2411)\end{array}$ & $\begin{array}{l}0.0417^{* * * *} \\
(2.2022)\end{array}$ & $\begin{array}{c}-0.0261 \\
(-1.3592)\end{array}$ & $\begin{array}{c}0.0280 \\
(1.2257)\end{array}$ & $\begin{array}{c}0.0126 \\
(0.5413)\end{array}$ & $\begin{array}{l}0.0715^{* * *} \\
(2.1730)\end{array}$ \\
\hline Pvt. Credit to GDP (log) & $\begin{array}{c}0.0450 * * * \\
(2.8626)\end{array}$ & $\begin{array}{c}0.0512 * * * \\
(3.3047)\end{array}$ & $\begin{array}{c}0.0433 * * \\
(2.1406)\end{array}$ & $\begin{array}{l}0.0493 * * \\
(2.5247)\end{array}$ & $\begin{array}{c}-0.0110 \\
(-0.5901)\end{array}$ & $\begin{array}{c}-0.0175 \\
(-1.0129)\end{array}$ & $\begin{array}{c}0.0061 \\
(0.3609)\end{array}$ & $\begin{array}{c}-0.0016 \\
(-0.0887)\end{array}$ & $\begin{array}{c}-0.0454 * * * \\
(-3.0372)\end{array}$ & $\begin{array}{c}-0.0702 * * * * \\
(-3.9079)\end{array}$ & $\begin{array}{c}-0.0296 \\
(-1.5656)\end{array}$ & $\begin{array}{c}-0.0643^{* * * *} \\
(-2.8420)\end{array}$ & $\begin{array}{c}-0.0021 \\
(-0.0939)\end{array}$ & $\begin{array}{l}-0.0464 * \\
(-1.7394)\end{array}$ & $\begin{array}{c}0.0049 \\
(0.2043)\end{array}$ & $\begin{array}{c}-0.0297 \\
(-0.8686)\end{array}$ \\
\hline Market Cap. To GDP (log) & $\begin{array}{c}-0.0806^{* * * *} \\
(-5.1849)\end{array}$ & $\begin{array}{c}-0.0338^{* * *} \\
(-2.2071)\end{array}$ & $\begin{array}{c}0.0209 \\
(1.0160)\end{array}$ & $\begin{array}{c}-0.0255 \\
(-1.2850)\end{array}$ & $\begin{array}{c}0.0149 \\
(0.8057)\end{array}$ & $\begin{array}{c}-0.0343^{* * *} \\
(-1.9908)\end{array}$ & $\begin{array}{c}-0.0034 \\
(-0.2127)\end{array}$ & $\begin{array}{l}-0.0233 \\
(-1.3636)\end{array}$ & $\begin{array}{c}-0.0564 * * * * \\
(-3.8146)\end{array}$ & $\begin{array}{c}-0.0142 \\
(-0.8013)\end{array}$ & $\begin{array}{c}-0.0124 \\
(-0.6472)\end{array}$ & $\begin{array}{c}-0.0161 \\
(-0.7001)\end{array}$ & $\begin{array}{c}0.0178 \\
(0.7996)\end{array}$ & $\begin{array}{c}0.0077 \\
(0.2914)\end{array}$ & $\begin{array}{c}0.0348 \\
(1.5458)\end{array}$ & $\begin{array}{c}0.0829 * * * * \\
(2.5976)\end{array}$ \\
\hline Law_wjp & $\begin{array}{c}0.5509 * * * \\
(3.5220)\end{array}$ & $\begin{array}{c}-0.0383 \\
(-0.2488)\end{array}$ & $\begin{array}{l}-0.1278 \\
(-0.7650)\end{array}$ & $\begin{array}{c}-0.5965 * * * \\
(-3.6963)\end{array}$ & $\begin{array}{c}-0.0846 \\
(-0.5966)\end{array}$ & $\begin{array}{c}-0.3717 * * * * \\
(-2.8202)\end{array}$ & $\begin{array}{c}-0.3084^{* * *} \\
(-2.5428)\end{array}$ & $\begin{array}{c}-0.4911 * * * \\
(-3.7380)\end{array}$ & $\begin{array}{l}0.2728^{*} \\
(1.8340)\end{array}$ & $\begin{array}{l}-0.2911 \\
(-1.6276)\end{array}$ & $\begin{array}{c}0.0813 \\
(0.5204)\end{array}$ & $\begin{array}{c}-0.3693^{* * *} \\
(-1.9752)\end{array}$ & $\begin{array}{c}0.0463 \\
(0.2711)\end{array}$ & $\begin{array}{l}-0.3922^{*} \\
(-1.9280)\end{array}$ & $\begin{array}{c}-0.4033^{* * *} \\
(-2.3303)\end{array}$ & $\begin{array}{c}-1.0403 * * * * \\
(-4.2423)\end{array}$ \\
\hline Industry Dummy & $\mathrm{Y}$ & $\mathrm{Y}$ & $\mathrm{Y}$ & $\mathrm{Y}$ & $\mathrm{Y}$ & $\mathrm{Y}$ & $\mathrm{Y}$ & $\mathrm{Y}$ & $\mathrm{Y}$ & $\mathrm{Y}$ & $\mathrm{Y}$ & $\mathrm{Y}$ & $\mathrm{Y}$ & $\mathrm{Y}$ & $\mathrm{Y}$ & $\mathrm{Y}$ \\
\hline Constant & $\begin{array}{c}0.4487 * * * * \\
(4.1139)\end{array}$ & $\begin{array}{l}0.2726 * * \\
(2.5374)\end{array}$ & $\begin{array}{l}-0.1060 \\
(-0.3640)\end{array}$ & $\begin{array}{c}0.0686 \\
(0.2439)\end{array}$ & $\begin{array}{c}0.3120 \\
(1.1781)\end{array}$ & $\begin{array}{c}0.6979 * * * \\
(2.8347)\end{array}$ & $\begin{array}{c}0.2234 \\
(1.4858)\end{array}$ & $\begin{array}{c}0.5197 * * * * \\
(3.1903)\end{array}$ & $\begin{array}{l}0.2320^{* * *} \\
(2.2371)\end{array}$ & $\begin{array}{c}0.1337 \\
(1.0721)\end{array}$ & $\begin{array}{c}-0.2675 \\
(-0.9828)\end{array}$ & $\begin{array}{l}-0.2687 \\
(-0.8245)\end{array}$ & $\begin{array}{c}0.1710 \\
(0.5364)\end{array}$ & $\begin{array}{c}0.0635 \\
(0.1671)\end{array}$ & $\begin{array}{c}-0.0778 \\
(-0.3625)\end{array}$ & $\begin{array}{c}-0.1957 \\
(-0.6435)\end{array}$ \\
\hline Observations & & & & & & & & & & & 1, & 1, & 1,4 & 1,4 & 1,492 & 1,492 \\
\hline R2 & 0.1812 & 0.1730 & 0.1722 & 0.2076 & 0.2277 & 0.2542 & 0.2972 & 0.2498 & 0.1320 & 0.1434 & 0.1381 & 0.1782 & 0.1400 & 0.2124 & 0.2272 & 0.1692 \\
\hline Adjusted R2 & 0.172 & 0.164 & 0.163 & 0.199 & 0.219 & 0.246 & 0.290 & 0.242 & 0.123 & 0.134 & 0.129 & 0.169 & 0.131 & 0.204 & 0.219 & 0.160 \\
\hline
\end{tabular}

on short-term and long-term debt-to-equity (market value \& book value). 
Table 9: Sample-level robustness tests by excluding USA and Japan firms.

\begin{tabular}{|c|c|c|c|c|c|c|c|c|c|c|c|c|}
\hline & $\begin{array}{l}\text { Short-term } \\
\text { debt to market } \\
\text { value of equity }\end{array}$ & $\begin{array}{l}\text { Short-term } \\
\text { debt to market } \\
\text { value of equity }\end{array}$ & $\begin{array}{l}\text { Short-term } \\
\text { debt to market } \\
\text { value of equity }\end{array}$ & $\begin{array}{l}\text { Short-term } \\
\text { debt to book } \\
\text { value of equity }\end{array}$ & $\begin{array}{l}\text { Short-term } \\
\text { debt to book } \\
\text { value of equity }\end{array}$ & $\begin{array}{l}\text { Short-term } \\
\text { debt to book } \\
\text { value of equity }\end{array}$ & $\begin{array}{l}\text { Long-term } \\
\text { debt to market } \\
\text { value of equity }\end{array}$ & $\begin{array}{l}\text { Long-term } \\
\text { debt to market } \\
\text { value of equity }\end{array}$ & $\begin{array}{l}\text { Long-term } \\
\text { debt to market } \\
\text { value of equity }\end{array}$ & $\begin{array}{l}\text { Long-term } \\
\text { debt to book } \\
\text { value of equity }\end{array}$ & $\begin{array}{l}\text { Long-term } \\
\text { debt to book } \\
\text { value of equity }\end{array}$ & $\begin{array}{l}\text { Long-term } \\
\text { debt to book } \\
\text { value of equity }\end{array}$ \\
\hline \multicolumn{13}{|l|}{ Hofstede Cultural Dimensions } \\
\hline Individualism & $\begin{array}{c}-0.0027 * * * \\
(-13.3021)\end{array}$ & & $\begin{array}{c}-0.0025 * * * \\
(-6.6605)\end{array}$ & $\begin{array}{c}-0.0031^{* * * * *} \\
(-15.3009)\end{array}$ & & $\begin{array}{c}-0.0018^{* * * *} \\
(-5.0228)\end{array}$ & $\begin{array}{c}0.0009^{* * * *} \\
(4.0088)\end{array}$ & & $\begin{array}{c}0.0004 \\
(0.9570)\end{array}$ & $\begin{array}{c}0.0025 * * * \\
(9.7469)\end{array}$ & & $\begin{array}{c}0.0020 * * * \\
(4.1883)\end{array}$ \\
\hline Masculinity & $\begin{array}{c}-0.0008 * * \\
(-2.4997)\end{array}$ & & $\begin{array}{c}-0.0009^{* * *} \\
(-2.3283)\end{array}$ & $\begin{array}{l}0.0005^{*} \\
(1.7436)\end{array}$ & & $\begin{array}{l}-0.0007 * \\
(-1.9215)\end{array}$ & $\begin{array}{c}-0.0010^{* * * *} \\
(-2.9963)\end{array}$ & & $\begin{array}{c}-0.0015 * * * * \\
(-3.7961)\end{array}$ & $\begin{array}{c}-0.0004 \\
(-0.9309)\end{array}$ & & $\begin{array}{c}-0.0015^{* * * *} \\
(-3.1293)\end{array}$ \\
\hline Uncertainty Avoidance & $\begin{array}{c}0.0008 * * * \\
(4.1348)\end{array}$ & & $\begin{array}{c}0.0014 * * * \\
(5.7693)\end{array}$ & $\begin{array}{c}-0.0004 * * \\
(-2.0455)\end{array}$ & & $\begin{array}{c}0.0000 \\
(0.0526)\end{array}$ & $\begin{array}{c}0.0007^{* * * *} \\
(3.4004)\end{array}$ & & $\begin{array}{c}0.0005^{* *} \\
(2.0039)\end{array}$ & $\begin{array}{l}-0.0005 * \\
(-1.9027)\end{array}$ & & $\begin{array}{c}-0.0008 * * * * \\
(-2.7314)\end{array}$ \\
\hline Long term Orientation & $\begin{array}{c}0.0009 * * * \\
(4.5784)\end{array}$ & & $\begin{array}{c}0.0008 * * * \\
(2.6182)\end{array}$ & $\begin{array}{c}0.0013 * * * * \\
(6.3636)\end{array}$ & & $\begin{array}{c}0.0019 * * * \\
(6.6053)\end{array}$ & $\begin{array}{c}0.0003 \\
(1.5383)\end{array}$ & & $\begin{array}{c}0.0002 \\
(0.5325)\end{array}$ & $\begin{array}{c}0.0004 \\
(1.5339)\end{array}$ & & $\begin{array}{c}0.0004 \\
(1.0726)\end{array}$ \\
\hline \multicolumn{13}{|l|}{ Firm-Level Variables } \\
\hline CAPEX / TA & & $\begin{array}{l}-0.1517^{*} \\
(-1.7562)\end{array}$ & $\begin{array}{c}-0.1724 * * \\
(-2.0620)\end{array}$ & & $\begin{array}{c}0.0894 \\
(1.0382)\end{array}$ & $\begin{array}{c}0.0728 \\
(0.8737)\end{array}$ & & $\begin{array}{c}0.5233^{* * * * * *} \\
(5.9442)\end{array}$ & $\begin{array}{c}0.5440 * * * \\
(6.1742)\end{array}$ & & $\begin{array}{l}1.1027^{* * * *} \\
(10.9641)\end{array}$ & $\begin{array}{c}0.8878 * * * \\
(8.3288)\end{array}$ \\
\hline EBIT / TA & & $\begin{array}{l}-0.7002 * * * \\
(-11.9868)\end{array}$ & $\begin{array}{c}-0.6431 * * * * \\
(-11.3688)\end{array}$ & & $\begin{array}{l}-0.7361 * * * \\
(-12.6373)\end{array}$ & $\begin{array}{c}-0.6684 * * * * \\
(-11.8498)\end{array}$ & & $\begin{array}{l}-0.9006 * * * \\
(-15.1278)\end{array}$ & $\begin{array}{l}-0.8978 * * * \\
(-15.0617)\end{array}$ & & $\begin{array}{l}-0.6189 * * * \\
(-10.0808)\end{array}$ & $\begin{array}{c}-0.7404 * * * * \\
(-10.2669)\end{array}$ \\
\hline SALES $(\log )$ & & $\begin{array}{c}-0.0020 \\
(-0.7748)\end{array}$ & $\begin{array}{c}0.0059 * * \\
(2.3075)\end{array}$ & & $\begin{array}{c}0.0071^{* * * *} \\
(2.8281)\end{array}$ & $\begin{array}{c}0.0124 * * * * \\
(4.8852)\end{array}$ & & $\begin{array}{c}0.0341 * * * \\
(13.2136)\end{array}$ & $\begin{array}{c}0.0354 * * * \\
(13.2423)\end{array}$ & & $\begin{array}{c}0.0562 * * * \\
(20.7508)\end{array}$ & $\begin{array}{c}0.0542 * * * \\
(16.7511)\end{array}$ \\
\hline TA Growth & & $\begin{array}{l}-0.0044^{*} \\
(-1.8218)\end{array}$ & $\begin{array}{c}-0.0048 * * \\
(-2.0168)\end{array}$ & & $\begin{array}{c}0.0052 * * \\
(2.1351)\end{array}$ & $\begin{array}{c}0.0037 \\
(1.5900)\end{array}$ & & $\begin{array}{l}-0.0046 * \\
(-1.8406)\end{array}$ & $\begin{array}{c}-0.0040 \\
(-1.6175)\end{array}$ & & $\begin{array}{c}0.0046 \\
(1.5067)\end{array}$ & $\begin{array}{c}0.0039 \\
(1.2892)\end{array}$ \\
\hline \multicolumn{13}{|l|}{ Country-Level Variables } \\
\hline GDP per Capita (log) & & $\begin{array}{c}-0.0580^{* * * *} \\
(-6.2523)\end{array}$ & $\begin{array}{c}-0.0688^{* * * *} \\
(-6.8176)\end{array}$ & & $\begin{array}{c}-0.0443 * * * \\
(-4.7904)\end{array}$ & $\begin{array}{c}-0.0280 * * * \\
(-2.7780)\end{array}$ & & $\begin{array}{c}-0.0095 \\
(-1.0030)\end{array}$ & $\begin{array}{c}-0.0126 \\
(-1.1822)\end{array}$ & & $\begin{array}{c}0.0604 * * * \\
(6.0885)\end{array}$ & $\begin{array}{c}0.0257 * * \\
(1.9973)\end{array}$ \\
\hline Pvt. Credit to GDP (log) & & $\begin{array}{c}0.0262 * * \\
(2.5755)\end{array}$ & $\begin{array}{c}0.0491 * * * * \\
(4.1192)\end{array}$ & & $\begin{array}{c}0.0597 * * * * \\
(5.8804)\end{array}$ & $\begin{array}{c}0.0436^{* * * * * *} \\
(3.6680)\end{array}$ & & $\begin{array}{c}-0.0435 * * * * \\
(-4.1933)\end{array}$ & $\begin{array}{c}-0.0395 * * * * \\
(-3.1447)\end{array}$ & & $\begin{array}{c}-0.0950 * * * * \\
(-9.2525)\end{array}$ & $\begin{array}{c}-0.0510 * * * * \\
(-3.3519)\end{array}$ \\
\hline Market Cap. To GDP (log) & & $\begin{array}{l}-0.0033 \\
(-0.3573)\end{array}$ & $\begin{array}{l}-0.0449 * * * * \\
(-4.2755)\end{array}$ & & $\begin{array}{l}-0.0034 \\
(-0.3688)\end{array}$ & $\begin{array}{l}-0.0435 * * * * \\
(-4.1527)\end{array}$ & & $\begin{array}{l}-0.0165 * \\
(-1.7543)\end{array}$ & $\begin{array}{l}-0.0116 \\
(-1.0521)\end{array}$ & & $\begin{array}{c}0.0417 * * * \\
(3.9940)\end{array}$ & $\begin{array}{l}-0.0004 \\
(-0.0333)\end{array}$ \\
\hline Law_wjp & & $\begin{array}{c}0.0664 \\
(0.8877)\end{array}$ & $\begin{array}{l}0.3273 * * * * \\
(3.2939)\end{array}$ & & $\begin{array}{c}-0.2862 * * * \\
(-3.8365)\end{array}$ & $\begin{array}{l}-0.2190^{* * *} \\
(-2.2100)\end{array}$ & & $\begin{array}{l}0.1247 \\
(1.6358)\end{array}$ & $\begin{array}{c}0.0351 \\
(0.3352)\end{array}$ & & $\begin{array}{c}-0.5335 * * * \\
(-6.4188)\end{array}$ & $\begin{array}{l}-0.3235 * * \\
(-2.5539)\end{array}$ \\
\hline Industry Dummy & $\mathrm{Y}$ & $\mathrm{Y}$ & $\mathrm{Y}$ & $\mathrm{Y}$ & $\mathrm{Y}$ & $\mathrm{Y}$ & $\mathrm{Y}$ & $\mathrm{Y}$ & $\mathrm{Y}$ & $\mathrm{Y}$ & $\mathrm{Y}$ & $\mathrm{Y}$ \\
\hline Constant & $\begin{array}{l}0.2074 * * * \\
(7.5931)\end{array}$ & $\begin{array}{c}0.6447 * * * \\
(10.3268)\end{array}$ & $\begin{array}{l}0.5931 * * * \\
(9.1826)\end{array}$ & $\begin{array}{l}0.2708 * * * * \\
(9.8734)\end{array}$ & $\begin{array}{l}0.5201 * * * * \\
(8.3557)\end{array}$ & $\begin{array}{l}0.5119 * * * \\
(7.9490)\end{array}$ & $\begin{array}{l}0.1718 * * * * \\
(5.8688)\end{array}$ & $\begin{array}{l}0.1272 * * \\
(1.9987)\end{array}$ & $\begin{array}{l}0.1738 * * \\
(2.5534)\end{array}$ & $\begin{array}{l}0.2539 * * * \\
(7.1405)\end{array}$ & $\begin{array}{c}-0.3376^{* * * *} \\
(-4.5395)\end{array}$ & $\begin{array}{l}-0.1105 \\
(-1.3422)\end{array}$ \\
\hline Firms (Countries) & 3,855 & 3 & 3, & 3, & 3,8 & 3,8 & 3,8 & 3,8 & 3,8 & 3,8 & 5,968 & 3,855 \\
\hline & 0.1157 & 0.1011 & 0.1644 & 0.1366 & 0.1348 & 0.1957 & 0.0700 & 0.1451 & 0.1505 & 0.1105 & 0.1844 & 0.1938 \\
\hline Adjusted R2 & 0.114 & 0.0983 & 0.161 & 0.135 & 0.132 & 0.192 & 0.0681 & 0.142 & 0.147 & 0.109 & 0.183 & 0.190 \\
\hline
\end{tabular}

$\mathrm{t}$-statistics in parentheses. ***p $<0.01, * * \mathrm{p}<0.05, * \mathrm{p}<0.1$. 
UAI has a significant negative association with firms LTD to book value of equity in quantiles except Q3. UAI has a significant positive association with firms LTD to market value of equity in Q3 and Q4. First, these results confirms our hypothesis H2c. Second, these contribute a new perspective to the culture and debt literature, which is only showing a negative association with LTD (Chang et al., 2012; Zheng et al., 2012). It contributes to a new cultural perspective to Ferris et al. (2018).

LTO has a significant positive association with STD to equity ratios in all quartiles meeting Chang et al. (2012) on LTO and debt maturity, confirming our hypothesis H2d. However, LTO has a significant positive association with LTD to equity ratios only in Q1, confirming that firms in LTO culture do not prefer taking long-term debt in their capital structure to avoid leaving debt-repayment risk for the future. This is key new contribution to the existing culture and debt literature (Chang et al., 2012; Zheng et al., 2012).

LTO has a significant positive association with firms LTD to book value of equity only in Q1. It confirms that firms from LTO cultures do not take higher risk in their capital structure, except the smallest firms. The ones who do are smaller firms. It may meet Ferris et al. (2018) in that when smaller firms market leverage fall below book leverage, they do not prefer taking additional debt.

Second sample-level test we perform is by removing firms from the USA and Japan (see table 9) to remove any possible large country sample bias. Main sample weight from these two countries being about $35 \%$. Our results show no change to our cultural dimensions signs compared to our main baseline results. However, LTO becomes insignificant for the LTD-to-equity ratios, probably due to the absence of Japanese firms in the tested sample.

\section{Conclusions}

The aim of this paper is to go deeper into the knowledge of national culture influence on firms' capital structure. Previous studies consider capital structure as a whole and rely on a single measure (Chui et al., 2002; Fauver \& McDonald, 2015). However, following Titman and Wessels (1998), we believe that more than one metric is necessary to have a comprehensive overview of firms' funding choices. That is why we opt for both short-term and long-term debt-to-equity ratios. It also allows us to complete the previous studies analyzing culture's relationship with firms' choice of debt-maturity (Zheng et al., 2012; Chang et al., 2012). Another key determinant of these choices is the market-timing (Baker \& Wurgler, 2002), meaning that firms take into account the dearness or the cheapness of their stocks on the market. This brings us to consider both the book and market value of equity.

This methodology allows us to encompass all the aspects of capital structure. By doing so, our findings throw more lights on the topic and offer a deeper understanding of the relationship puzzle between 
culture and capital structure. We bring the empirical evidence that firms' country-of-origin clearly influences their choices of financing.

As said above, our contributions extends the earlier literature by highlighting that national culture influences all the metrics of capital structure. It appears to be a key determinant of both short-term and long-term debt-to-equity ratios. As expected, these ratios exhibit different patterns and they are not similarly affected by cultural dimensions. In accordance with the market timing approach of capital structure (Baker \& Wurgler, 2002), we find different results when we consider the market value of equity instead of its book value.

The first set of results is based on the long-term debt-to-equity. We find that firms' country-of-origin cultural dimensions of high individualism, low masculinity, low uncertainty avoidance, and high longterm orientation have a positive relationship with their long-term debt-to-equity book values. High individualism, low masculinity, high uncertainty avoidance have a positive relationship with firms' long-term debt-to-equity market value.

The second set of results is based on the short-term debt-to-equity. These findings highlight the fact that the influence of national culture lingers even when we consider the effects of the momentum of capital markets. In this case, we find that low individualism, low masculinity, and high long-term orientation influence firms' choices of short-term debt-to-equity book value. Low individualism, low masculinity, high uncertainty avoidance, and high long-term orientation influence firms' choices of short-term debtto-equity market values. These results confirm that national culture is somewhat stronger that market forces.

Our results would mean that firms with higher long-term debt-to-book values are from high individualism and low uncertainty avoidance countries such as the United States, Great Britain, Canada, or Australia. Furthermore, firms with higher long-term debt-to-market values are rather from low masculine countries such as Denmark, Finland, Norway, and Sweden or from high uncertainty avoidance countries such as France, Belgium, Turkey, or Israel.

Similarly, our findings underline those firms with higher short-term debt-to-book values would rather be from low individualism, high uncertainty avoidance, and high long-term orientation countries such as Japan, South Korea, or Taiwan. These firms may also be from low masculine countries that are Denmark, Finland, Norway, or Sweden. Furthermore, firms with higher short-term debt-to-market values would be from the same countries but in lower numbers.

Our research highlights that despite an increasing international trade context, the firm's country-oforigin culture matters in its financial choices. Two firms from different country-of-origin cultures may differ in their capital structures, despite being in the same industry sector. Those capital structure 
differences may not necessarily indicate differences in firms' business performances or long-term sustainability. Capital structure differences may rather indicate differences in firms' risk-taking. The differences in risk-taking are due to firms' national culture values (Li et al., 2013; Pan et al, 2017). Therefore, firms make different financing choices aligned with their national culture values (Chui et al., 2002; Fauver \& McDonald, 2015; Chang et al., 2012; Zheng et al., 2012). Firms investments from the financing raised may differ (Titman, S., \& Wessels, R, 1988). These investments decisions also embed firms country-of-origin culture nuances (Carr \& Tomkins, 1998).

All in all -despite cultural differences- firms common quest of optimal capital structure to meet their profit and value maximizing goals remains. In line with existing capital structure theory, firms' risktaking may guide their choice of optimal debt-to-equity mix (Myers, 1984). Furthermore, firms' may extract optimal financing by timing it to the higher of their equity's book or market value (Baker \& Wurgler, 2002; Ferris et al., 2018). Therefore, our findings are relevant to international corporate finance managers, investors, and creditors in analyzing and comparing firms' balance sheets. They should base their analysis on several metrics of firms' capital structure in relation with firms' country-of-origin cultural values. It would allow all stakeholders to better interpret capital structures distances between firms in the same industry sector but from different country-of-origin cultures.

The supposed misalignment between capital structure of firms belonging to the same industry but originating from two countries should be explained by different national cultures. This finding also support the framework proposed by Williamson (2000) and teaches us that the financial choices made by firms are not only about the bottom line of the financial statements. They also are in line with the behavior of managers, firms and institutions, which all are rooted in the culture of their country-oforigin. 


\section{Annexure}

Table 1: Hofstede's cultural dimensions correlation matrix (VSM2015 dataset).

Correlation matrix for Hofstede six cultural dimensions for 66 countries (including the Arab cluster)

\begin{tabular}{|c|c|c|c|c|c|c|}
\hline & PDI & IDV & MAS & UAI & LTO & IVR \\
\hline PDI & 1.0000 & & & & & \\
\hline IDV & $-0.6473 * * *$ & 1.0000 & & & & \\
\hline MAS & 0.1660 & 0.0083 & 1.0000 & & & \\
\hline UAI & 0.1671 & -0.1599 & 0.0437 & 1.0000 & & \\
\hline LTO & 0.0031 & 0.1115 & -0.0163 & -0.0477 & 1.0000 & \\
\hline IVR & $-0.2600 * *$ & 0.1086 & 0.1209 & -0.0345 & $-0.5193 * * *$ & 1.0000 \\
\hline
\end{tabular}




\section{References}

Appelbaum, S. H., Audet, L., \& Miller, J. C. (2003). Gender and leadership? Leadership and gender? A journey through the landscape of theories. Leadership \& Organization Development Journal, 24(1), 43-51. doi : 10.1108/01437730310457320.

Ardalan, K. (2007). Corporate governance: a paradigmatic look. International Journal of Social Economics 34(8), 506-524. doi: $10.1108 / 03068290710763035$.

Ardalan, K. (2017). Capital structure theory: Reconsidered. Research in International Business and Finance, 39, 696-710. doi:10.1016/j.ribaf.2015.11.010.

Baker, M., \& Wurgler, J. (2002). Market timing and capital structure. The journal of finance, 57(1), 1-32. doi.org/10.1111/1540-6261.00414 .

Botero, J. C., \& Ponce, A. (2011). Measuring the rule of law. Available at SSRN 1966257, doi:10.2139/ssrn.1966257.

Campbell, G., \& Rogers, M. (2018). Capital structure volatility in Europe. International Review of Financial Analysis, 55, 128-139. doi : 10.1016/j.irfa.2017.11.008 .

Carr, C., \& Tomkins, C. (1998). Context, culture and the role of the finance function in strategic decisions. A comparative analysis of Britain, Germany, the USA and Japan. Management Accounting Research, 9(2), 213-239. doi:10.1006/mare.1998.0075.

Chang, K., Wee, J. B., \& Yi, H. C. (2012). Does national culture influence the firm's choice of debt maturity? Asia-Pacific Journal of Financial Studies, 41(4), 424-457. doi:10.1111/j.2041-6156.2012.01078.x.

Chen, Y., Dou, P. Y., Rhee, S. G., Truong, C., \& Veeraraghavan, M. (2015). National culture and corporate cash holdings around the world. Journal of Banking \& Finance, 50, 1-18. doi:10.1016/j.jbankfin.2014.09.018.

Chui, A. C., Lloyd, A. E., \& Kwok, C. C. (2002). The Determination of Capital Structure: Is National Culture a Missing Piece to the Puzzle ? Journal of international business studies, 33(1), 99-127. doi:10.1057/palgrave.jibs.8491007.

Demirgüç-Kunt, A., \& Maksimovic, V. (1998). Law, finance, and firm growth. The Journal of Finance, 53(6), 2107-2137. doi:10.1111/00221082.00084 .

Djankov, S., McLiesh, C., \& Shleifer, A. (2007). Private credit in 129 countries. Journal of financial Economics, 84(2), 299-329. doi : 10.1016/j.jfineco.2006.03.004

Fauver, L., \& McDonald, M. B. (2015). Culture, agency costs, and governance: International evidence on capital structure. Pacific-Basin Finance Journal, 34, 1-23. doi : 10.1016/j.pacfin.2015.05.001

Ferris, S. P., Hanousek, J., Shamshur, A., \& Tresl, J. (2018). Asymmetries in the Firm's use of debt to changing market values. Journal of Corporate Finance, 48, 542-555. doi:10.1016/j.jcorpfin.2017.12.006

Fidrmuc, J. P., \& Jacob, M. (2010). Culture, agency costs, and dividends. Journal of Comparative Economics, 38(3), 321-339. doi:10.1016/j.jce.2010.04.002

Frank, M. Z., \& Goyal, V. K. (2009). Capital structure decisions: which factors are reliably important? Financial management, $38(1)$, 1-37. doi:10.1111/j.1755-053x.2009.01026.x.

Fuchs-Schündeln, N., Masella, P., \& Paule-Paludkiewicz, H. (2017). Cultural Determinants of Household Saving Behavior. Working Paper.

Gleason, K. C., Mathur, L. K., \& Mathur, I. (2000). The interrelationship between culture, capital structure, and performance: evidence from European retailers. Journal of business research, 50(2), 185-191.

Hancock, G. R., Mueller, R. O., \& Stapleton, L. M. (2010). The reviewer's guide to quantitative methods in the social sciences. Routledge. doi:10.4324/9781315755649.

Harris, M., \& Raviv, A. (1991). The theory of capital structure. The Journal of Finance, 46(1), 297-355. doi : 10.1111/j.15406261.1991.tb03753x

Hofstede, G. (1980). Culture's consequences: International differences in work-related values. Beverly Hills, CA: Sage.

Hofstede, G. (2001). Culture's consequences: Comparing values, behaviors, institutions and organizations across nations. Thousand Oaks, CA: 2nd ed. Sage.

Hofstede, G., G. J. Hofstede, \& M. Minkov. (2010). Cultures and organizations: software of the mind. New York: McGraw-Hill.

Jensen, M. C., \& Meckling, W. H. (1976). Theory of the firm: Managerial behavior, agency costs and ownership structure. Journal of financial economics, 3(4), 305-360. doi: 10.1016/0304-405x(76)90026-x .

Kim, E. H. (1982). Miller's equilibrium, shareholder leverage clienteles, and optimal capital structure. The Journal of Finance, 37(2), 301-319.

Kraus, A., \& Litzenberger, R. H. (1973). A state-preference model of optimal financial leverage. The journal of finance, $28(4)$, $911-922$. doi: $10.2307 / 2978343$

Kwok, C. C., \& Tadesse, S. (2006). National culture and financial systems. Journal of International business studies, 37(2), 227-247. doi:10.1057/palgrave.jibs.8400188.

La Porta, R., Lopez-de-Silanes, F., \& Shleifer, A. (2008). The economic consequences of legal origins. Journal of economic literature, 46(2), 285-332. doi:10.1257/jel.46.2.285.

Lagoarde-Segot, T. (2016). Prolegomena to an Alternative Study of Finance. In R. P. Bernard Paranque, Finance Reconsidered: New Perspectives for a Responsible and Sustainable Finance (pp. 89-110). Emerald Books. doi:10.1108/s2043-905920160000010024.

Li, K., Griffin, D., Yue, H., \& Zhao, L. (2013). How does culture influence corporate risk-taking? Journal of Corporate Finance, 23 , 1-22. doi:10.1016/j.jcorpfin.2013.07.008.

Licht, A. N., Goldschmidt, C., \& Schwartz, S. H. (2005). Culture, law, and corporate governance. International review of law and economics, 25(2), 229-255. doi:10.1016/j.irle.2005.06.005.

MacKay, P., \& Phillips, G. M. (2005). How does industry affect firm financial structure? The Review of Financial Studies, $18(4), 1433-1466$. doi:10.1093/rfs/hhi032.

Modigliani, F., \& Miller, M. H. (1958). The cost of capital, corporation finance and the theory of investment. The American economic review, $48(3), 261-297$.

Myers, S. C. (1984). The capital structure puzzle. The journal of finance, 39(3), 574-592. doi:10.1111/j.1540-6261.1984.tb03646.x.

Myers, S. C. (2001). Capital structure. The journal of economic perspectives, 15(2), 81-102. doi:10.1257/jep.15.2.81.

Navidi, W. C. (2008). Statistics for engineers and scientists (pp. 344-354). New York, NY, USA: McGraw-Hill Higher Education.

Noorderhaven, N. G., \& Harzing, A. W. (2003). The "country-of-origin effect" in multinational corporations: Sources, mechanisms and moderating conditions. Management and International Review, 47-66, Gabler Verlag, Wiesbaden. doi:10.1007/978-3-322-909954_4

North, D. C. (1991). Institutions. Journal of economic perspectives, 5(1), 97-112. doi:10.1257/jep.5.1.97.

Pan, Y., Siegel, S., \& Wang, T. Y. (2017). Corporate risk culture. Journal of Financial and Quantitative Analysis, 52(6), $2327-2367$. doi:10.1017/s0022109017000771

Porta, R. L., Lopez-de-Silanes, F., Shleifer, A., \& Vishny, R. W. (1998). Law and finance. Journal of political economy, 106(6), $1113-115$. doi: $10.1086 / 250042$ 
Rajan, R. G., \& Zingales, L. (1995). What do we know about capital structure? Some evidence from international data. The journal of finance, 50(5), 1421-1460.

Shleifer, A., \& Vishny, R. W. (1997). A survey of corporate governance. The journal of finance, 52(2), 737-783. doi:10.1111/j.15406261.1997.tb04820.x.

Titman, S., \& Wessels, R. (1988). The determinants of capital structure choice. The Journal of finance, 43(1), 1-19. doi:10.1111/j.15406261.1988.tb02585.x.

Wijayana, S., \& Gray, S. J. (2018). Capital market consequences of cultural influences on earnings: The case of cross-listed firms in the US stock market. International Review of Financial Analysis, 57, 134-147. doi: 10.1016/j.irfa.2018.03.007.

Williamson, O. E. (2000). The new institutional economics: taking stock, looking ahead. Journal of economic literature, $38(3)$, $595-613$. doi:10.1257/jel.38.3.595.

Zheng, X., El Ghoul, S., Guedhami, O., \& Kwok, C. C. (2012). National culture and corporate debt maturity. Journal of Banking \& Finance, 36(2), 468-488. doi:10.1016/j.jbankfin.2011.08.004. 